University of Nebraska - Lincoln

DigitalCommons@University of Nebraska - Lincoln

U.S. National Park Service Publications and

Papers

National Park Service

2-2021

\title{
Protocol for Monitoring Aquatic Invertebrates of Small Streams in the Heartland Inventory \& Monitoring Network, Version 2.1
}

\author{
David E. Bowles \\ United States National Park Service \\ Michael H. Williams \\ United States National Park Service \\ Hope R. Dodd \\ United States National Park Service \\ Lloyd W. Morrison \\ United States National Park Service \\ Janice A. Hinsey

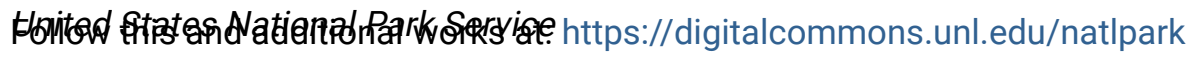 \\ Part of the Aquaculture and Fisheries Commons, Environmental Education Commons, Environmental \\ Belinyexpagerior Gddittómaeatathotsdies Commons, Fire Science and Firefighting Commons, Leisure \\ Studies Commons, Natural Resource Economics Commons, Natural Resources Management and Policy \\ Commons, Nature and Society Relations Commons, Other Environmental Sciences Commons, Physical \\ and Environmental Geography Commons, Public Administration Commons, and the Recreation, Parks and \\ Tourism Administration Commons
}

Bowles, David E.; Williams, Michael H.; Dodd, Hope R.; Morrison, Lloyd W.; Hinsey, Janice A.; Cribbs, J. Tyler; Rowell, Gareth A.; DeBecker, Michael D.; Haack-Gaynor, Jennifer L.; and Williams, Jeffrey M., "Protocol for Monitoring Aquatic Invertebrates of Small Streams in the Heartland Inventory \& Monitoring Network, Version 2.1" (2021). U.S. National Park Service Publications and Papers. 224.

https://digitalcommons.unl.edu/natlpark/224

This Article is brought to you for free and open access by the National Park Service at DigitalCommons@University of Nebraska - Lincoln. It has been accepted for inclusion in U.S. National Park Service Publications and Papers by an authorized administrator of DigitalCommons@University of Nebraska - Lincoln. 


\section{Authors}

David E. Bowles, Michael H. Williams, Hope R. Dodd, Lloyd W. Morrison, Janice A. Hinsey, J. Tyler Cribbs, Gareth A. Rowell, Michael D. DeBecker, Jennifer L. Haack-Gaynor, and Jeffrey M. Williams 


\section{Protocol for Monitoring Aquatic Invertebrates of Small Streams in the Heartland Inventory \& Monitoring Network}

\section{Version 2.1}

Natural Resource Report NPS/HTLN/NRR—2021/2229

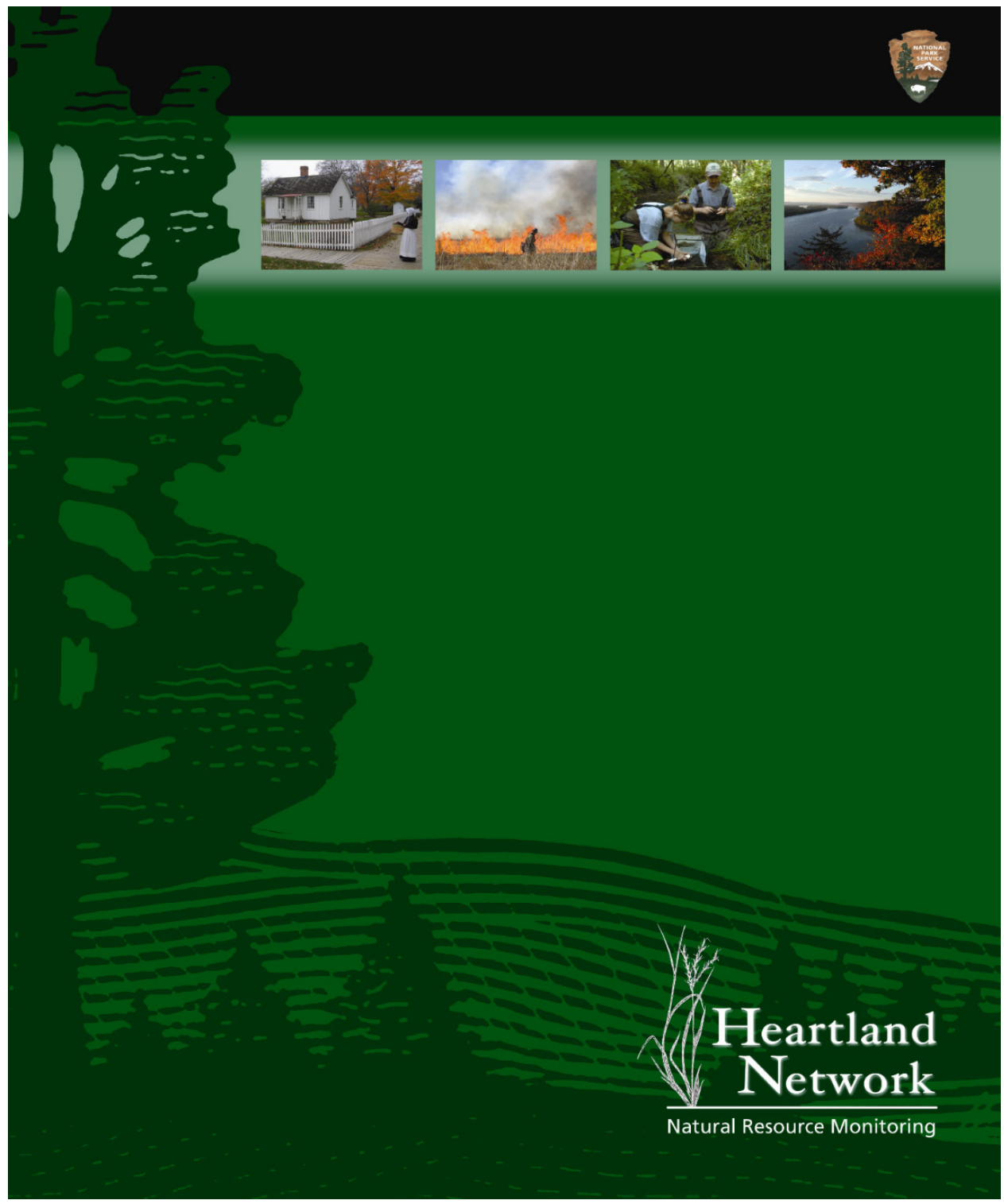


ON THE COVER

Herbert Hoover birthplace cottage at Herbert Hoover National Historic Site, prescribed fire at Tallgrass Prairie National Preserve, aquatic invertebrate monitoring at George Washington Carver National Monument, and the Mississippi River at Effigy Mounds National Monument.

Photography by NPS 


\section{Protocol for Monitoring Aquatic Invertebrates of Small Streams in the Heartland Inventory \& Monitoring Network}

\section{Version 2.1}

Natural Resource Report NPS/HTLN/NRR-2021/2229

David E. Bowles, ${ }^{1}$ Michael H. Williams, ${ }^{1}$ Hope R. Dodd,${ }^{1}$ Lloyd W. Morrison, ${ }^{1}$ Janice A. Hinsey ${ }^{1}$ J. Tyler Cribbs, ${ }^{1}$ Gareth A. Rowell, ${ }^{1}$ Michael D. DeBacker, ${ }^{1}$ Jennifer L. Haack-Gaynor, ${ }^{1}$ and Jeffrey M. Williams ${ }^{2}$

${ }^{1}$ National Park Service

Heartland I\&M Network

Wilson's Creek National Battlefield

6424 West Farm Road 182

Republic, Missouri 65738

${ }^{2}$ Missouri State University

Department of Biology

901 South National Avenue

Springfield, Missouri 65897

Editing and Design by

Tani Hubbard

National Park Service \&

Northern Rockies Conservation Cooperative

12661 E. Broadway Blvd.

Tucson, AZ 85748

February 2021

U.S. Department of the Interior

National Park Service

Natural Resource Stewardship and Science

Fort Collins, Colorado 
The National Park Service, Natural Resource Stewardship and Science office in Fort Collins, Colorado, publishes a range of reports that address natural resource topics. These reports are of interest and applicability to a broad audience in the National Park Service and others in natural resource management, including scientists, conservation and environmental constituencies, and the public.

The Natural Resource Report Series is used to disseminate comprehensive information and analysis about natural resources and related topics concerning lands managed by the National Park Service. The series supports the advancement of science, informed decision-making, and the achievement of the National Park Service mission. The series also provides a forum for presenting more lengthy results that may not be accepted by publications with page limitations.

All manuscripts in the series receive the appropriate level of peer review to ensure that the information is scientifically credible, technically accurate, appropriately written for the intended audience, and designed and published in a professional manner.

This report received formal peer review by subject-matter experts who were not directly involved in the collection, analysis, or reporting of the data, and whose background and expertise put them on par technically and scientifically with the authors of the information.

Views, statements, findings, conclusions, recommendations, and data in this report do not necessarily reflect views and policies of the National Park Service, U.S. Department of the Interior. Mention of trade names or commercial products does not constitute endorsement or recommendation for use by the U.S. Government.

This report is available from the Heartland Network Inventory and Monitoring website and the Natural Resource Publications Management website. If you have difficulty accessing information in this publication, particularly if using assistive technology, please email irma@nps.gov.

Please cite this publication as:

Bowles, D. E., M. H. Williams, H. R. Dodd, L. W. Morrison, J. A. Hinsey, J. T. Cribbs, G. A. Rowell, M. D. DeBacker, J. L. Haack-Gaynor, and J. M. Williams. 2021. Protocol for monitoring aquatic invertebrates of small streams in the Heartland Inventory \& Monitoring Network: Version 2.1. Natural Resource Report NPS/HTLN/ NRR—2021/2229. National Park Service, Fort Collins, Colorado. https://doi.org/10.36967/nrr-2284622.

NPS 920/175075, February 2021 


\section{Contents}

Figures

Tables

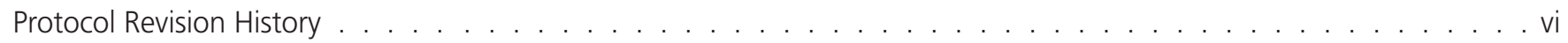

Standard Operating Procedures . . . . . . . . . . . . . . . . . . . . . . . . . . . . . . . . . . .

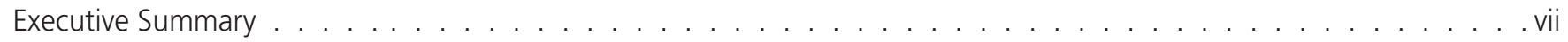

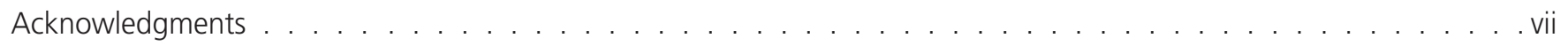

Heartland Inventory and Monitoring Network . . . . . . . . . . . . . . . . . . . . . . viii

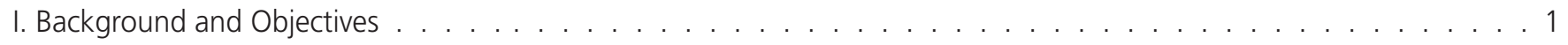

Issues Being Addressed and Rationale for Monitoring Benthic Invertebrates . . . . . . . . . . . . . . 1

History of Invertebrate Monitoring in Midwestern NPS Parks . . . . . . . . . . . . . . . . . 1

Revision of the Peterson et al. 1999 Protocol . . . . . . . . . . . . . . . . . . . 2

Revision of the Bowles et al. 2008 Protocol . . . . . . . . . . . . . . . . . . . . . . 4

Measurable Objectives . . . . . . . . . . . . . . . . . . . . . . . . . . . . . . . . . 4

Operational Objectives . . . . . . . . . . . . . . . . . . . . . . . 4

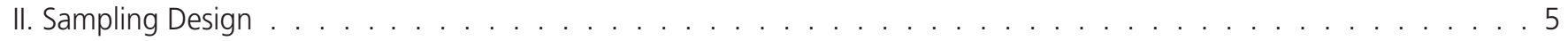

Rationale for the Sampling Design . . . . . . . . . . . . . . . . . . . . . . 5

State Monitoring Programs . . . . . . . . . . . . . . . . . . . . . . . . . . . . 5

Federal Monitoring Programs . . . . . . . . . . . . . . . . . . . . . . . 6

Spatial Design . . . . . . . . . . . . . . . . . . . . . . . . . . . 8

Establishing the Sample Frame . . . . . . . . . . . . . . . . . . . . . . . . . . 8

Sampling Sites and Reach Selection . . . . . . . . . . . . . . . . . . . . . 8

Sample Placement . . . . . . . . . . . . . . . . . . . . . . . . 10

Temporal Design . . . . . . . . . . . . . . . . . . . . . . . . . . . . . 11

Response Design . . . . . . . . . . . . . . . . . . . . . . . . . . . 12

Types of Data Collected in the Field . . . . . . . . . . . . . . . . . . . 12

Sampling Devices . . . . . . . . . . . . . . . . . . . . . . . . . . . . . . . 12

Number of Samples . . . . . . . . . . . . . . . . . . . . . . . . . . . . 12

Suitability of Survey Design to Meet Study Objectives . . . . . . . . . . . . . . . . . . . 13

III. Field and Laboratory Methods . . . . . . . . . . . . . . . . . . . . . . . . . . . . . . . . . 14

Field Season Preparations, Field Schedule, and Equipment Setup . . . . . . . . . . . . . . . . . . . . 14

Collecting Benthic Invertebrate Samples and Associated Habitat and Water Quality Data . . . . . . . . . . . 14

Benthic Sample Processing and Specimen Identification . . . . . . . . . . . . . . . . . . . . 16

Subsampling Benthic Samples . . . . . . . . . . . . . . . . . . . . . . . . . 16 


\section{Contents (continued)}

Sample Storage and Reference Collection . . . . . . . . . . . . . . . . . . . . . . . . . . . . 16

Post Season Procedures . . . . . . . . . . . . . . . . . . . . . . . . . . . . . . 16

IV. Data Management ． . . . . . . . . . . . . . . . . . . . . . . . . . . . . . . . . . . . . . . . . . . . 17

Overview of Database Design . . . . . . . . . . . . . . . . . . . . . . . . . . 17

Quality Assurance and Quality Control . . . . . . . . . . . . . . . . . . . . . . . . 17

Metadata Procedures . . . . . . . . . . . . . . . . . . . . . . . . . . 17

Data Archival Procedures . . . . . . . . . . . . . . . . . . . . . . . . . . . . . . . . . . 18

V. Data Summary, Analysis, and Reporting . . . . . . . . . . . . . . . . . . . . . . . . . . . . . . . . . 19

Metric Selection and Community Indices . . . . . . . . . . . . . . . . . . . . . . . . 19

EPT Richness . . . . . . . . . . . . . . . . . . . . . . . . . . . . . . . . . . . . . . 19

EPT Ratio $(\mathrm{R}) \ldots \ldots \ldots \ldots \ldots \ldots \ldots$

Taxa Richness . . . . . . . . . . . . . . . . . . . . . . . . . . . . . . . . . . . . . . . . . . . . . . . . 19

Taxa Diversity . . . . . . . . . . . . . . . . . . . . . . . . . . . . . . . . 20

Genus Evenness . . . . . . . . . . . . . . . . . . . . . . . . . . . . . . 20

Biotic Indices . . . . . . . . . . . . . . . . . . . . . . . . . . . . . . . . . . . 20

Data Analysis . . . . . . . . . . . . . . . . . . . . . . . . . . . . . . . . . . 20

Bayesian Methods . . . . . . . . . . . . . . . . . . . . . . . . . . . . . . 21

Hypothesis Testing . . . . . . . . . . . . . . . . . . . . . . . . . . . 21

Parameter Estimation . . . . . . . . . . . . . . . . . . . . . . . . . . . . . . . . 21

Control Charts . . . . . . . . . . . . . . . . . . . . . . . . . . . . . . . . . . 21

Power Analysis . . . . . . . . . . . . . . . . . . . . . . . . . . . . . . . . . 22

Other Statistical Tests . . . . . . . . . . . . . . . . . . . . . . . . . 22

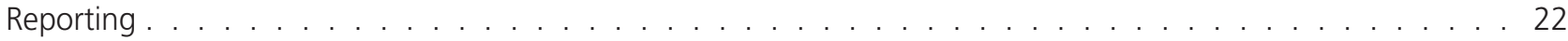

Vl. Personnel Requirements and Training . . . . . . . . . . . . . . . . . . . . . . 23

Roles and Responsibilities . . . . . . . . . . . . . . . . . . . . . . . . . . . 23

Qualifications and Training . . . . . . . . . . . . . . . . . . . . . . . 23

VII. Operational Requirements . . . . . . . . . . . . . . . . . . . . . . . . . . . . . . . . . . . . . . . 24

Field Schedule . . . . . . . . . . . . . . . . . . . . . . . . . . . . . . . . . . . . . . . . . . . . . . . . . . . . 24

Facility and Equipment Requirements . . . . . . . . . . . . . . . . . . . . . . . 24

Budget Considerations . . . . . . . . . . . . . . . . . . . . . . . . . . . . . . 24

VIll. Procedures for Protocol Revision . . . . . . . . . . . . . . . . . . . . . . . . . . . . . . . . . 25

IX. Literature Cited . . . . . . . . . . . . . . . . . . . . . . . . . . . . . . . . . . . . 26

Appendix A. Maps of Stream Locations . . . . . . . . . . . . . . . . . . . . . . . . . . . . . . 33 


\section{Figures}

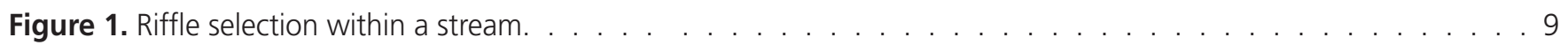

Figure 2. Placement of Surber samples within a single riffle . . . . . . . . . . . . . . . . . . 10

Figure 3. Placement of Hester-Dendy samplers in Cub Creek, HOME. . . . . . . . . . . . . . . . . . 10

Figure 4. Flow of work diagram for collecting Surber samples. . . . . . . . . . . . . . . . . . 14

Figure 5. Flow of work diagram for collecting Hester-Dendy samples. . . . . . . . . . . . . . . . . . 15

\section{Tables}

Table 1. Summary of changes between the former protocol (Peterson et al. 1999) and the Bowles et al.

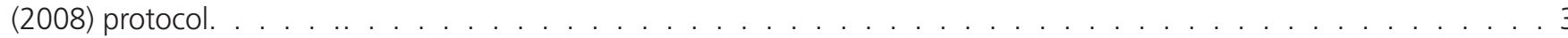

Table 2. The streams to be sampled in each network park and the corresponding index period recom-

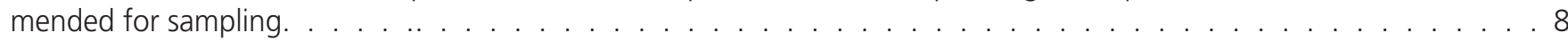

Table 3. Revisit design for invertebrate monitoring in small streams at Heartland I\&M Network parks. . . . . . . . . . 11 


\section{Protocol Revision History}

The original protocol narrative version 1.0 was published in 2008 (Bowles et al. 2008). This document is protocol version 2.1. Changes made to the SOPs since the first versions were published are referenced in the individual SOPs.

Revision History Log
\begin{tabular}{|l|l|l|l|l|l|}
\hline $\begin{array}{l}\text { Prev. } \\
\text { Version \# }\end{array}$ & $\begin{array}{l}\text { Revision } \\
\text { Date }\end{array}$ & Author (s) & Changes made & Reason for Change & $\begin{array}{l}\text { New } \\
\text { Version \# }\end{array}$ \\
\hline 1.0 & $12 / 2019$ & $\begin{array}{l}\text { David E. Bowles, Michael H. } \\
\text { Williams, Hope R. Dodd, Lloyd } \\
\text { W. Morrison, Janice A. Hinsey, J. } \\
\text { Tyler Cribbs, Gareth A. Rowell, } \\
\text { Michael D. DeBacker, Jennifer } \\
\text { L. Haack-Gaynor, and Jeffrey M. } \\
\text { Williams }\end{array}$ & $\begin{array}{l}\text { Minor updates and expansion and } \\
\text { clarification of the narrative. SOP\#7 } \\
\text { (Data Management), SOP\#8 (Data } \\
\text { Analysis), and SOP\#9 (Data Report- } \\
\text { ing) were updated and expanded. }\end{array}$ & $\begin{array}{l}\text { Clarifies understand- } \\
\text { ing of procedures } \\
\text { and incorporates } \\
\text { new guidance where } \\
\text { appropriate. }\end{array}$ & 2.0 \\
\hline 2.0 & $07 / 2020$ & $\begin{array}{l}\text { David E. Bowles, Michael H. } \\
\text { Williams, Hope R. Dodd, Lloyd } \\
\text { W. Morrison, Janice A. Hinsey, J. } \\
\text { Tyler Cribbs, Gareth A. Rowell, } \\
\text { Michael D. DeBacker, Jennifer } \\
\text { L. Haack-Gaynor, and Jeffrey M. } \\
\text { Williams }\end{array}$ & $\begin{array}{l}\text { Minor formatting updates and } \\
\text { minor wording changes to reflect } \\
\text { new version. }\end{array}$ & Discoverability & 2.1 \\
\hline
\end{tabular}

\section{Standard Operating Procedures}

The following standard operating procedures (SOPs) are published as separate documents.

SOP 1. Preparation for Field Sampling and Laboratory Processing

SOP 2. Training for Field Sampling and Laboratory Processing

SOP 3. Sampling Invertebrates and Collecting Habitat Data

SOP 4. Documenting CORE 5 Water Quality Variables

SOP 5. Measuring Stream Discharge

SOP 6. Laboratory Processing and Identification of Invertebrates

SOP 7. Data management

SOP 8. Data analysis

SOP 9. Reporting

SOP 10. Procedures and Equipment Storage After Field Season Completion

SOP 11. Revising the protocol 


\section{Executive Summary}

The Heartland Inventory and Monitoring Network (HTLN) is a component of the National Park Service's (NPS) strategy to improve park management through greater reliance on scientific information. The purposes of this program are to design and implement long-term ecological monitoring and provide information for park managers to evaluate the integrity of park ecosystems and better understand ecosystem processes. Concerns over declining surface water quality have led to the development of various monitoring approaches to assess stream water quality. Freshwater streams in network parks are threatened by numerous stressors, most of which originate outside park boundaries. Stream condition and ecosystem health are dependent on processes occurring in the entire watershed as well as riparian and floodplain areas; therefore, they cannot be manipulated independently of this interrelationship. Land use activities_-such as timber management, landfills, grazing, confined animal feeding operations, urbanization, stream channelization, removal of riparian vegetation and gravel, and mineral and metals mining - threaten stream quality. Accordingly, the framework for this aquatic monitoring is directed towards maintaining the ecological integrity of the streams in those parks.

Invertebrates are an important tool for understanding and detecting changes in ecosystem integrity, and they can be used to reflect cumulative impacts that cannot otherwise be detected through traditional water quality monitoring. The broad diversity of invertebrate species occurring in aquatic systems similarly demonstrates a broad range of responses to different environmental stressors. Benthic invertebrates are sensitive to the wide variety of impacts that influence Ozark streams. Benthic invertebrate community structure can be quantified to reflect stream integrity in several ways, including the absence of pollution sensitive taxa, dominance by a particular taxon combined with low overall taxa richness, or appreciable shifts in community composition relative to reference condition. Furthermore, changes in the diversity and community structure of benthic invertebrates are relatively simple to communicate to resource managers and the public. To assess the natural and anthropogenic processes influencing invertebrate communities, this protocol has been designed to incorporate the spatial relationship of benthic invertebrates with their local habitat including substrate size and embeddedness, and water quality parameters (temperature, dissolved oxygen, $\mathrm{pH}$, specific conductance, and turbidity). Rigid quality control and quality assurance are used to ensure maximum data integrity. Detailed standard operating procedures (SOPs) and supporting information are associated with this protocol.

\section{Acknowledgments}

We thank the peer reviewers whose comments improved upon the original protocol. We also thank the many people who helped us in the field as we undertook the first few years of monitoring that led to this revised protocol. 


\section{Heartland Inventory and Monitoring Network}

The National Park Service has organized its parks with significant natural resources into 32 networks linked by geography and shared natural resource characteristics. The Heartland Inventory and Monitoring (I\&M) Network (Heartland Network) is composed of 15 NPS units in eight Midwestern states. These parks contain a wide variety of natural and cultural resources, including sites focused on commemorating civil war battlefields, Native American heritage, westward expansion, and our U.S. Presidents. The Network is charged with creating inventories of its species and natural features as well as monitoring trends and issues in order to make sound management decisions. Critical inventories help park managers understand the natural resources in their care while monitoring programs help them understand meaningful change in natural systems and to respond accordingly. The Heartland Network helps to link natural and cultural resources by protecting the habitat of our history.

The I\&M program bridges the gap between science and management with a third of its efforts aimed at making information accessible. Each network of parks, such as the Heartland Network, has its own multi-disciplinary team of scientists, support personnel, and seasonal field technicians whose system of online databases and reports make information and research results available to all. Greater efficiency is achieved through shared staff and funding as these core groups of professionals augment work done by individual park staff. Through this type of integration and partnership, network parks are able to accomplish more than a single park could on its own.

The mission of the Heartland Network is to collaboratively develop and conduct scientifically credible inventories and long-term monitoring of park vital signs and to distribute this information for use by park staff, partners, and the public, thus enhancing understanding which leads to sound decision making in the preservation of natural resources and cultural history held in trust by the National Park Service.

\section{https://www.nps.gov/im/htln/index.htm}

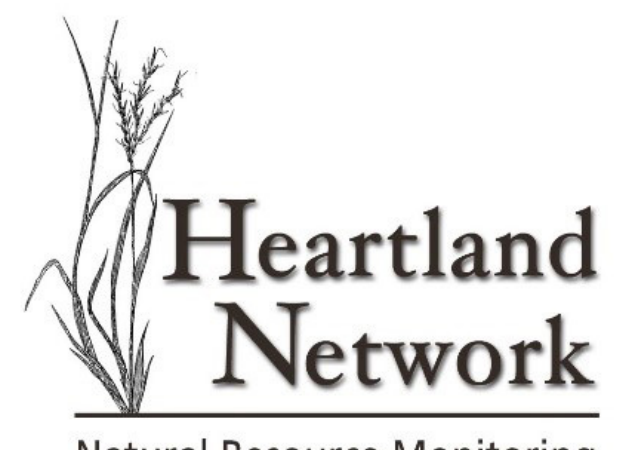

Natural Resource Monitoring 


\section{Background and Objectives}

\section{Issues Being Addressed and Rationale for Monitoring Benthic Invertebrates}

The condition of streams is a direct reflection of the extent of development and other human uses in the watershed. Non-point source pollution-including urban and agricultural runoff, treated sewage, and changes in hydrology - threaten water quality and quantity of streams. Due to these threats, streams are among the most vulnerable natural resources in the United States (USEPA 2006). Furthermore, streams in the Midwestern U.S. are among the most impacted because the long history of land use in this region, including extensive agriculture and development, has influenced virtually all waterbodies in the region (Hall et al. 2003; Dodds et al. 2004; USEPA 2006).

The Heartland Inventory and Monitoring Network (HTLN) is a major component of the National Park Service's (NPS) strategy to improve park management through greater reliance on scientific information. The purposes of this program are to design and implement long-term ecological monitoring and provide information for park managers to evaluate the integrity of park ecosystems, including streams, and better understand ecosystem processes. Concerns over declining surface water quality have led to the development of various monitoring approaches to assess stream water quality in those systems. Benthic aquatic invertebrates are a diverse group of localized species that often react strongly and predictably to human disturbance, making them a cost-effective and conservative tool to monitor stream water quality. Aquatic invertebrates are an important biological tool for understanding and detecting changes in stream ecosystem integrity, and they can be used to reflect cumulative impacts that cannot otherwise be detected through traditional water quality monitoring. The broad diversity of invertebrate species occurring in aquatic systems similarly demonstrates a broad range of responses to different environmental and anthropogenic stressors.

Benthic invertebrates are relatively easy to collect, and they can be analyzed at many different levels of precision. They are sensitive to a wide variety of impacts that occur in the region, such as changes in chemical constituents, hydrological alterations, sedimentation and bank erosion, and land use and other changes in the watershed (Hall et al. 2003).
Furthermore, changes in the diversity and community structure of benthic invertebrates are relatively simple to communicate to resource managers, administrators, and park visitors because the loss of biological communities is of interest and concern to these groups. Benthic community structure can be quantified to reflect stream integrity in several ways, including the absence of pollution sensitive taxa, dominance by a particular taxon combined with low overall taxa richness, or appreciable shifts in community composition relative to reference conditions (Plafkin et al. 1989; Lazorchak et al. 1998; Barbour et al. 1999; USEPA 2006).

To assess the natural and anthropogenic processes influencing invertebrate communities, this protocol has been designed to incorporate the spatial relationship of invertebrates with their associated habitat. Local variables, such as conductivity, water temperature, $\mathrm{pH}$, dissolved oxygen, turbidity, current velocity, substrate size, and other habitat variables will be measured.

\section{History of Invertebrate Monitoring in Midwestern NPS Parks}

In the late 1980s, the NPS began an intensive program to monitor water quality and invertebrate community structure in prairie streams at Agate Fossil Beds National Monument (AGFO), Homestead National Monument of America (HOME), Pipestone National Monument (PIPE), and Wilson's Creek National Battlefield (WICR; Harris et al. 1991). The initial strategy for sampling streams in these parks was presented in a manual by Boyle et al. (1990). Data collected in 1988-1989 at WICR and 1989 at PIPE, AGFO, and HOME, in addition to data collected from Herbert Hoover National Historic Site (HEHO) and George Washington Carver National Monument (GWCA), are summarized in Harris et al. (1991, 1999). A preliminary protocol was suggested by Peterson (1996), in which data dating back to 1988 and collected under the guidance described in Boyle et al. (1990) were analyzed. An official invertebrate biomonitoring protocol, drawing heavily on Peterson's (1996) results, was published in 1999 (Peterson et al. 1999). Although the first sampling associated with this protocol was conducted in 1988, Peterson (1996) considered 1989 as the baseline year, because it was the first year with reasonably 
thorough sampling (Peterson et al. 1999). The Peterson protocol was implemented in four parks (AGFO, HOME, PIPE, and WICR), and no further monitoring was conducted at HEHO. Similarly, Peterson (1997) monitored invertebrates at GWCA in 1996 using methods similar to those described in the 1999 protocol, but no further monitoring was conducted at this park until 2005.

Peitz and Cribbs (2005a, b, c) summarized all historic invertebrate monitoring data from HOME, PIPE, and WICR and included interpretations of the data in their reports. The various data summarized by Peitz and Cribbs indicated there has not been a precipitous decline in stream condition at these parks since monitoring was first initiated, and in general, stream condition has largely remained stable. Similarly, the monitoring data in Harris et al. (1991) and Peterson (1997) suggest the streams at GWCA were not degraded at the time of sampling. However, the data for HEHO, although limited and inconclusive, suggest Hoover Creek may be degraded given the low scores for taxa richness; Ephemeroptera, Plecoptera, and Trichoptera (EPT) richness; and Shannon's index. Although not collected under NPS protocols, Foreman (2007) completed a study of water quality in Hoover Creek at HEHO that included a multihabitat assessment of the aquatic invertebrate community at four sites using IOWATER Advanced Benthic Macroinvertebrate Indexing methods. The IOWATER methods are a modification of the Environmental Protection Agency (EPA) Environmental Monitoring and Assessment Program (EMAP) protocol (Lazorchak et al. 1998). The data presented by Foreman (2007) strongly suggest that Hoover Creek is degraded with respect to the invertebrate community. Summary data for AGFO (Peitz and Cribbs 2005d) are not included here because monitoring was no longer conducted at the park by the HTLN after 2007.

The most recent data summaries for all of the parks included in this protocol can be found in Bowles 2015; Bowles 2010a, b, 2013a, b; Bowles and Clark 2012; and Bowles et al. 2013, 2016, 2017, 2018. Additional reports are cited in those references.

\section{Revision of the Peterson et al. (1999) Protocol}

The Inventory \& Monitoring (I\&M) Program of the NPS has embraced high standards for monitoring protocols. HTLN staff completed a comprehensive review of the Peterson et al. (1999) protocol for sampling invertebrates in small streams, the relevant documents preceding and succeeding it, and the way that the data have been collected and analyzed. These documents included a report written in 2003 by Dr. Larissa Bailey (USGS Patuxent Wildlife Research Center, Laurel, MD) that provided short-term statistical analysis and advice concerning data collected under Peterson et al. (1999; unpublished report and email communications). This review revealed a critical need to revise the guidance issued in Peterson et al. (1999).

Morrison and Bowles (2006) presented further recommendations for modifying the original protocol to bring it in line with other existing nationallevel protocols and allow for the collection of statistically robust and scientifically defensible data. A number of potential improvements were identified to better meet program goals and objectives. These were included in the Bowles et al. (2008) protocol and are described below. The implemented changes do not preclude comparibility with the early dataset (i.e., 1988-2005) obtained by collaborators at Colorado State University and subsequent monitoring. Indeed, data collected using the guidance of Bowles et al. (2008) are quite similar to the historical data. The exception is lower genus richness scores for some parks under the newer protocol because members of the family Chironomidae are no longer identified to genus. A summary of the changes is shown in Table 1.

The most significant change described in Bowles et al. (2008) compared to Peterson et al. (1999) was the addition of monitoring at Effigy Mounds National Monument (EFMO), GWCA, Hot Springs National Park (HOSP), HEHO, and Tall Grass Prairie National Preserve (TAPR). In addition, Terrell Creek (WICR) was added as an additional monitoring site. Terrell Creek became part of WICR in 2005 when the park expanded its jurisdictional boundary. AGFO was no longer sampled under this protocol because it is part of the Northern Great Plains Inventory and Monitoring Network.

Other major changes from Peterson et al. (1999) to Bowles et al. (2008) included the following.

- Historically, the parks listed under the Peterson et al. (1999) monitoring protocol were sampled monthly for three consecutive months each summer. We reduced the number of sampling events to one visit every three years. This allowed us to 
Table 1. Summary of changes between the former protocol (Peterson et al. 1999) and the Bowles et al. (2008) protocol.

\begin{tabular}{|l|l|l|}
\hline Change Made & Peterson et al. 1999 Protocol & Bowles et al. 2008 Protocol \\
\hline Number of parks & 4 & 9 \\
\hline Sampling sites per stream & $1-2$ per stream & 1 per stream \\
\hline Sampling frequency & 3 times per year & Once every 3 years \\
\hline Number of riffles/sites per stream & 5 & 3 \\
\hline Number of samples per riffle & 1 & 3 \\
\hline $\begin{array}{l}\text { Total number of samples per } \\
\text { stream per date }\end{array}$ & $5-10$ & 9 \\
\hline Sampling device & Surber sampler/Hester-Dendy & Surber sampler/Hester-Dendy \\
\hline Mesh size of sampling device & $263 \mu$ m & $500 \mu$ m \\
\hline Subsampled portion of sample & $20 \%$ & $25 \%$ \\
\hline Metrics & Described in Data Analysis section & No major changes \\
\hline Depth and current velocity & Meter stick displacement & Wading rod and flow meter \\
\hline Substrate assessment & $\begin{array}{l}\text { Percentage composition estimate of silt, } \\
\text { sand, gravel, cobble within 1 m of sample }\end{array}$ & Dominant size (Wentworth Scale) in sample frame \\
\hline Stream discharge & No & Yes \\
\hline Water quality & Static CORE 5 readings (hand-held meters) & Unattended hourly CORE 5 readings (datasonde) \\
\hline
\end{tabular}

1 Two historic sampling sites at HOME will be maintained.

${ }^{2}$ Hester-Dendy samplers are used only at HOME.

sample more streams in more parks compared to the previous protocol.

- At some parks, where two sites had been monitored on a stream (WICR and PIPE), only a single sampling site was recommended per stream. The stream segments in the respective parks are short $(\leq 2 \mathrm{~km})$, monitoring two sites does not enhance the ability to detect impairment, and sampling from a single stream reach is considered generally adequate to represent a stream segment (Rabeni et al. 1999; Gregg and Stednick 2007). Although Rabeni et al. (1999) defined a single stream reach as 20 times the stream width and encompassing approximately 2 riffle/pool sequences, stream reach as used here under the newer protocol effectively met this description due to the short lengths of the streams sampled. Both historical sampling sites were maintained at HOME because of a different collection methodology used and to provide a sample size comparable to that for other parks.

- The mesh size of the Surber sampler was increased to $500 \mu \mathrm{m}$ from the original $263 \mu \mathrm{m}$. This change was justified because (1) increasing the mesh size results in little appreciable change in the number and diversity of invertebrates collected (Morin et al. 2004), (2) the larger mesh size is used in other national level monitoring protocols, and (3) debris and sediments often clog the finer mesh resulting in backflow from the net and reduced capture efficiency.

- The percentage of each sample that is subsampled was increased from $20 \%$ to $25 \%$.

- No major changes were proposed for the metrics calculated from the benthic data, however, a change was made to the calculation of the diversity indices. The Hilsenhoff Biotic Index and Shannon Evenness Index previously used family level identification and the new procedure used genus level to allow a more precise estimate of community tolerance and evenness. Also, total density was no longer tracked for Hester-Dendy plate samples. Although invertebrate densities may decrease when communities are exposed to certain stressors (Resh and Grodhaus 1983; Plafkin et al. 1989), they are notoriously variable under normal conditions (Chutter 1972; Kroger 1972) and can provide misleading results. Finally, members of the family Chironomidae were no longer identified to genus. This change 
only impacted genus richness and diversity scores causing them to be lower than previously recorded. This change was made because processing, mounting, and identifying chironomids involved considerable staff time that could not be met given other monitoring-related demands on staff time.

- Physical habitat data collection was modified as follows:

- Depth $(\mathrm{cm})$ and current velocity $(\mathrm{m} / \mathrm{sec})$ was measured directly in front of the collection net using a calibrated flow meter (see SOP\#5, Measuring Stream Discharge, for details) attached to a wading rod rather than using the previous and highly inaccurate method of vertical displacement with a meter stick.

- Substrate was assessed as the dominant substrate size represented within the sampling net frame based on the Wentworth Scale (Wentworth 1922; see SOP\#3, Sampling Invertebrates and Collecting Habitat Data, for details). This approach replaced the previous method of visually estimating the percentage composition of four different substrate type categories (i.e., silt, sand, gravel, cobble) within $1 \mathrm{~m}$ of the sampling site.

- Stream discharge $\left(\mathrm{m}^{3} / \mathrm{sec}\right)$ was collected for each stream sampled and was not previously measured.

- A data sonde was deployed for a minimum of 24 hours for each stream to collect continuous hourly CORE 5 water quality data (temperature, dissolved oxygen, $\mathrm{pH}$, specific conductance, and turbidity) rather than relying on static readings for each riffle using hand-held meters.

Sampling frequency changed from three times per year to once every three years. A potential disadvantage of this change is that it may take longer to detect changes or significant trends in stream condition.

\section{Revision of the Bowles et al. (2008) Protocol}

Changes made to the Bowles et al. (2008) protocol included minor updates and and clarification of the narrative. The most substantial change was to data management and reporting, which were broadened to reflect the latest NPS guidance on data quality assurance and quality control. Some of the SOPs were also updated: SOP\#7 (Data Management), SOP\#8 (Data Analysis), and SOP\#9 (Data Reporting). They were modified to reflect the latest NPS guidance (SOP\#7, SOP\#9) or to streamline and clarify supporting language for a better understanding of statistical tests needed for analysis (SOP\#8). No substantial changes were made to field or laboratory operating procedures. Changes from the version 2.0 protocol to this new version 2.1 protocol include minor formatting changes and the addition of a DOI number.

\section{Measurable Objectives}

Aquatic invertebrates are an important biomonitoring tool for understanding and detecting changes in ecosystem integrity over time. Therefore, two broad measurable monitoring objectives of this protocol as described by DeBacker et al. (2005) are as follows.

1. Determine the status and trends of invertebrate species diversity, abundance, and community metrics.

2. Relate the invertebrate community to overall water quality through quantification of metrics related to species richness, abundance, and diversity and region-specific multimetric indices as indicators of water quality and habitat condition (DeBacker et al. 2005).

Justification/Rationale for these Objectives: Aquatic invertebrates are an important biomonitoring tool for understanding and detecting changes in ecosystem integrity over time. Aquatic invertebrates respond rapidly to different environmental stressors, are relatively easy to collect, and can be analyzed at many different levels of precision.

\section{Operational Objectives}

1. Communicate monitoring results to park natural resource managers, other park staff, and partners, including outreach efforts when appropriate. Furthermore, contributions to the scientific community may be valuable.

2. Conduct monitoring safely, ideally without accident or injury. Safe monitoring includes during transportation to/from parks as well as during field operations. 


\section{Sampling Design}

A long-term monitoring program must specify how to efficiently sample numerous parameters through space and time. An overall sampling design must contain multiple components including (1) a spatial design (how sample sites are located and the area of statistical inference), (2) a revisit design (how frequently sites are sampled), and (3) a response design (how and what data are collected).

\section{Rationale for the Sampling Design}

The streams sampled under this monitoring protocol are located among six states (AR, IA, KS, MO, MN, and NE) representing several EPA Level III Ecoregions (i.e., Ozark Highlands, Ouachita Mountains, Flint Hills, Central Great Plains, and Western Corn Belt Plains).

\section{State Monitoring Programs}

Most of the host states for the network parks included in this protocol employ a wide variety of approaches and methodologies to assess benthic invertebrate communities and their respective relationship to water quality. In some instances, the data collected under these various programs are not directly comparable. The state of Arkansas presently does not have a statewide protocol for assessing invertebrate communities in streams. The Arkansas Department of Environmental Quality presently is developing a statewide monitoring program based on EPA EMAP.

The state of Missouri uses a multimetric index called the Stream Condition Index (SCI) that was developed by Rabeni et al. (1997). The SCI is based on four metrics as measures of community structure and balance. These metrics are taxa richness, EPT (Ephemeroptera, Plecoptera, Trichoptera) richness, Shannon's Diversity Index, and Biotic Index (BI). These and other community metrics are described in Barbour et al. (1999). All metric values are normalized so that they become unitless and can be comparable and have equal influence on the SCI results. Reference data collected from throughout Missouri were used to determine a range for each metric with one of three possible scores assigned to each range. The scores are based on the lower or upper quartile of the distribution for each metric depending on whether it decreases or increases due to impairment.
The scores are then used as the minimum value representative of reference conditions. The four scores are summed to generate the SCI score. Scores range from 16-20 for not impaired, 10-14 for impaired, and $4-8$ for very impaired.

The Iowa Department of Natural Resources (IDNR) employs a biological assessment of wadeable streams (Wilton 2004) that is strongly based on the EPA EMAP approach (see discussion on this approach below). The IDNR used biological sampling data from reference sites to develop a Benthic Macroinvertebrate Index of Biotic Integrity (BMIBI). The BMIBI is comprised of twelve metrics that reflect a broad range of aquatic community attributes, and reference site sampling data was used to develop metric calculation formulas that transform raw individual metric values into a normalized score ranging from 0 (poor) to 10 (optimum). The normalized and combined metric scores range from $0-30$ for poor, 31-55 for fair, 56-75 for good, and 76-100 for excellent.

Since 1994, the Nebraska Department of Environmental Quality (NDEQ) has employed a rotating basin approach for water quality assessment monitoring based on the EPA's Regional Environmental Monitoring and Assessment Program (REMAP; Bazata 2005). The monitoring strategy targets resources in two or three river basins annually to allow for intensive efforts to increase the identification and abatement of pollution problems. All 13 water basins in Nebraska are monitored over 5 years. Approximately 40 biological monitoring sites are selected randomly each year from the perennial streams within the water basin of interest for that year. Sample sites are selected to best represent monitoring objectives and are based on professional judgment.

The Minnesota Pollution Control Agency (MPCA) has used benthic invertebrates as indicators of human disturbance of aquatic resource integrity for the past 25 years. The MPCA approach is generally based on the methods of the USEPA and used a multihabitat sampling approach. Between 1976 and 1979 the MPCA collected invertebrate community data from 21 stream stations throughout the state to assess water quality. Between 1990 and 1992, 
invertebrates were collected at 45 stream stations through the Minnesota River Basin (Genet and Chirhart 2004). An IBI developed by Ohio EPA for the Eastern Cornbelt Plain was used as a means for assessing aquatic resource integrity. The MPCA has biological and stream water chemistry data for several locations on Pipestone Creek in Pipestone National Monument (PIPE); the most recent available data from MPCA are from 2017 (MPCA 2018). No reports further summarizing or interpreting these data are available from MPCA.

The Kansas Department of Health and Environment (KDHE) conducts stream invertebrate monitoring as part of their Stream Biological Monitoring Program (KDHE 2000). The KDHE approach is based on two independently collected 100-organism samples collected in the field by two scientists that are used to calculate the four metrics. The metrics used include the Kansas Biological Index (KBI), the macroinvertebrate biotic index (MBI), EPT (Ephemeroptera, Plecoptera, Trichoptera) richness, and EPT (\%) abundance to assess stream integrity. Each metric is scored and assigned to one of three aquatic life-support categories: fully supporting, partially supporting, and non-supporting (Poulton et al. 2007). The KDHE has previously conducted invertebrate community assessments in the Fox Creek Watershed, which includes sites on Fox Creek and its tributary, Palmer Creek. The data collected by the KDHE suggested moderate impairment in these two streams and that nitrification from animal wastes and fertilizer is the primary source of the disturbance. These data have not been published, but are available from the KDHE as part of the Neosho River Basin total maximum daily load.

\section{Federal Monitoring Programs}

Programs to monitor stream condition are used by the US Environmental Protection Agency (EPA), US Geological Survey (USGS), and the National Park Service (NPS) Heartland Inventory and Monitoring Network (HTLN).

\section{USGS NAWQA}

The general basis of the USGS National WaterQuality Assessment (NAWQA) program is to collect biological, physical, and chemical data at stream reaches that have major natural and anthropogenic factors considered responsible for controlling water quality in a river basin. Two broad types of benthic samples are collected from these sampling reaches to characterize the invertebrate community: (1) semiquantitative benthic samples collected from targeted habitat types (i.e., richest targeted habitat or RTH), and (2) a composite qualitative sample collected from a broad variety of habitats throughout the reach (i.e., qualitative multihabitat or QMH).

The RTH theoretically supports the faunistically richest invertebrate community and is typically represented by a coarse-grained riffle or a woody snag. The semiquantitative RTH sample consists of a series of discrete collections (Moulton et al. 2002). The semiquantitative benthic samples recommended by NAWQA are collected from the RTH (riffles in most cases) using a Slack-Surber sampler $\left(0.25 \mathrm{~m}^{2}\right.$; Moulton et al. 2002). The number of individual benthic samples to be collected under the NAWQA protocol depends on study objectives. The NAWQA protocol generally recommends selecting a single riffle where at least five discrete collections can be taken. Collected samples are partially processed in the field and subsequently composited into a single bulk sample. By compositing the individual samples collected from a reach, no estimate of variability among samples can be obtained. The NAWQA protocol allows for location of sites based on representativeness of the local area, given that the location supports project objectives. This gives the site investigator flexibility in establishing site boundaries depending on local conditions.

\section{EPA}

The EPA has two programs for assessing water quality using invertebrate communities in wadeable streams. These are the Rapid Bioassessment Protocols for Use in Streams and Rivers (Barbour et al. 1999), and the Environmental Monitoring and Assessment Program-Surface Waters (EMAP; Lazorchak et al. 1998). An additional set of protocols designed for larger non-wadeable rivers (Flotemersch et al. 2006) generally are not applicable to the streams in the network parks and are not further addressed here.

\section{Rapid Bioassessment}

The Rapid Bioassessment approach uses either single habitat (e.g., riffles) or multihabitat approaches. Both approaches involve collecting samples from a $100-\mathrm{m}$ reach determined by the investigator to be representative of the characteristics of the stream. The single 
habitat approach involves sampling using a kick-net to sample approximately $1 \mathrm{~m}$ in front of the net, and taking 2-3 kicks using foot agitation. The samples are then composited for analysis. Benthic metrics for analyzing data are the same or comparable to those used in this protocol (Barbour et al. 1999). The multihabitat approach uses 20 jabs or kicks taken from different representative habitat types within the reach using a D-frame dipnet. Samples are composited for analysis and metrics are the same or comparable to those used in this protocol (Barbour et al. 1999).

\section{EMAP}

The EMAP approach focuses on evaluating ecological conditions on regional and national scales. It uses probabilistically selected sites where individual sampling sites are assessed using a transect-based design where community biological metrics are tied to habitat structure. Kick net samples collected from flowing water habitats (e.g., riffles, runs) are combined into a single composite sample for the stream reach, while kick net samples collected from pool habitats are combined into a separate composite sample. The kick net used in the EMAP method is effectively the same net as a Slack-Surber sampler minus the frame delineating the sampling area in front of the net. Data are analyzed following Barbour et al. (1999) and use either multimetric or multivariate approaches. In addition, some programs use $\mathrm{O} / \mathrm{E}$ (Observed/Expected) Ratio of Taxa Loss to assess invertebrate community degradation. This tool is a ratio comparing the number of taxa expected (E) to exist at a site to the number that are actually observed (O). The taxa expected at individual sites are based on models developed from data collected at reference sites. The current protocol does not use $\mathrm{O} / \mathrm{E}$ ratios.

The EPA's Wadeable Streams Assessment Program is based on the EMAP approach and is not considered separately here (USEPA 2004a, b, c, d).

\section{HTLN}

The HTLN developed a monitoring protocol for large rivers and their tributaries within network parks that is generally based on the NAWQA approach (Bowles et al. 2007). This HTLN monitoring approach uses multiple randomly selected sampling reaches where three benthic samples are collected from each of three consecutive riffles. Samples are analyzed separately and are not composited, allowing for variability to be assessed. Also, qualitative, multihabitat samples are not collected under the HTLN protocol. Collection methods and sample processing otherwise follow NAWQA.

There are some similarities among the EPA, NAWQA, and HTLN approaches that will allow for comparison of data. In support of this statement, Peterson and Zumberge (2006) generally found no significant differences between invertebrate samples collected from riffles using the NAWQA and EMAP protocols. Also, Herbst and Silldorff (2006) reported that, while methodological uniformity is important when coordinating monitoring programs, data from multiple sources could potentially be used interchangeably and for cross-validation of assessments of stream biological integrity. Herbst and Silldorff (2006) further noted that differing bioassessment methods can yield similar data and effectively discriminate impaired biological condition even though they have multiple differences in field and laboratory protocols.

The small streams sampling approach described here is based primarily upon that of the HTLN large rivers protocol (Bowles et al. 2007). However, this protocol differs from the large rivers protocol to account for maintaining comparability with historical monitoring data and because of limitations posed by staff size and logistical and budgetary constraints. For example, because the length of the streams inside the park boundaries is relatively short (3 $\mathrm{km}$ or less), this protocol will use a single sampling reach for each stream sampled, rather than multiple reaches. This approach is the same as that used by Bowles et al. (2007) for small tributaries that are similar in size to those in the small stream parks. Also, the sampling device proposed for use in this protocol is the Surber stream bottom sampler $\left(0.093 \mathrm{~m}^{2}\right)$ rather than the Slack Surber sampler $\left(0.25 \mathrm{~m}^{2}\right)$ recommended by the HTLN large river protocol. We propose to use the former sampler because it has been used historically for sampling invertebrates in many of the included network parks. We also will continue to use HesterDendy multiplate samplers at Homestead National Monument of America (HOME) because they have been used historically for this purpose, and their continued use favors comparison of data. 


\section{Spatial Design}

\section{Establishing the Sample Frame}

This protocol focuses on aquatic invertebrate communities occurring in small, wadeable streams within the NPS jurisdictional boundaries at each of the included parks.

Boyle et al. (1990) did not specify how sites were selected, simply referring to them as sentinel sites. Harris et al. (1991) gave a written description of the locations of each site. As Peterson et al. (1999) later pointed out, no criteria were given for site selection. However, historical sampling sites were frequently near upstream and downstream park boundaries, and accessibility was apparently an important concern. In fact, most historical sites were located near park roads or trails, indicating convenience was an important component in site selection. Peterson et al. (1999) recommended continued use of these established sites, presumably to allow for comparisons with the earlier data.

This protocol retains the historical collection sites, but only includes the downstream-most sites in parks with two historical sampling sites, with the exception of HOME. The problem with choosing sites based on such criteria is that, statistically speaking, any results obtained from such a design are applicable only to the specific locations sampled and not the entire stream running through the park. However, given the short length of the streams to be sampled, this shortcoming is not an overriding concern in light of maintaining comparability with historical data. Furthermore, sampling from a single stream reach (defined as 1 riffle-pool-riffle sequence) is generally considered adequate to represent a stream segment (Rabeni et al. 1999; Gregg and Stednick 2007).

Gebler (2004) reported that the number of sampled reaches required to obtain Minimum Detectable Differences (MDD) of $\leq 20 \%$ ranged in the tens to hundreds of reaches. However, for this protocol, such a large number of sampling sites would not be feasible because of budgetary and staffing constraints and the relatively small physical size of the streams themselves.

\section{Sampling Sites and Reach Selection}

This protocol recommends invertebrate monitoring in 18 streams located among 9 parks (Table 2 and Appendix A maps). The sampling index period

Table 2. The streams to be sampled in each network park and the corresponding index period recommended for sampling.

\begin{tabular}{|c|c|c|c|}
\hline Park & Streams sampled & $\begin{array}{l}\text { UTM Coordinates } \\
\text { (Northing, Easting) }\end{array}$ & Index Period \\
\hline \multirow[t]{3}{*}{ GWCA } & Carver Creek & $4094380.11,379254.85$ & May-June \\
\hline & Harkins Branch & $4094493.46,378963.70$ & May-June \\
\hline & Williams Branch & $4094466.25,379268.19$ & May-June \\
\hline EFMO & Dousman Creek & $4772108.08,645475.84$ & July-August \\
\hline HEHO & Hoover Creek & $4614462.87,637697.89$ & July-August \\
\hline \multirow[t]{2}{*}{ HOME } & Cub Creek (North) & $4462337.67,684059.84$ & August-September \\
\hline & Cub Creek (West) & $446166.50,683530.90$ & August-September \\
\hline \multirow[t]{2}{*}{ HOSP } & Bull Bayou & $3819096.45,489743.19$ & June-July \\
\hline & Gulpha Creek & $3820036.11,496779.10$ & June-July \\
\hline \multirow[t]{3}{*}{ PERI } & Pratt Creek & $4033256.21,407127.86$ & May-June \\
\hline & Winton Spring Branch & $4033296.3,407032.2$ & May-June \\
\hline & Lee Creek & $4033355.5,406034$ & May-June \\
\hline PIPE & Pipestone Creek & $4877259.61,714204.77$ & July-September \\
\hline \multirow[t]{2}{*}{ TAPR } & Fox Creek & $4256985.51,713944.53$ & April-May \\
\hline & Palmer Creek & $4263176.10,710907.56$ & April-May \\
\hline \multirow[t]{3}{*}{ WICR } & Skegg's Branch & $4105745.65,463391.47$ & May- June \\
\hline & Terrell Creek & $4104000.832,462818.328$ & May- June \\
\hline & Wilson's Creek & $4104580.870,464167.047$ & May- June \\
\hline
\end{tabular}


assigned to each stream is primarily based on an examination of the historical dataset from 1988 to 2004 . Rationale for using these index periods is presented below under Temporal Design.

At George Washington Carver National Monument (GWCA), PIPE, and Wilson's Creek National Battlefield (WICR), only the downstream-most historical sampling sites are sampled. At Cub Creek (HOME), both historical sites will be maintained. Using two sampling sites at HOME is based in part on the use of a different methodology and in part because it will provide a sample size comparable to that of the other parks. For all other streams added to this newer protocol, a sampling reach was selected from the downstream-most portion of each stream within the jurisdictional boundaries of a park. The selected sampling sites were located upstream of the apparent floodplain of any larger tributaries when applicable. Riffle selection was determined $a$ priori, with the three riffles sampled being those located in consecutive order upstream of the first riffle above the lower reach boundary (Figure 1). In some cases, the first upstream riffle in a stream was located a considerable distance from the park boundary (i.e., Tallgrass Prairie National Preserve, TAPR). Sampling reaches identified in this protocol are permanent, but the specific locations of the riffles sampled in a given year may move naturally due to hydrological processes. General directions to the sampling sites within a park are listed in SOP \#3 (Sampling Invertebrates and Collecting Habitat Data).

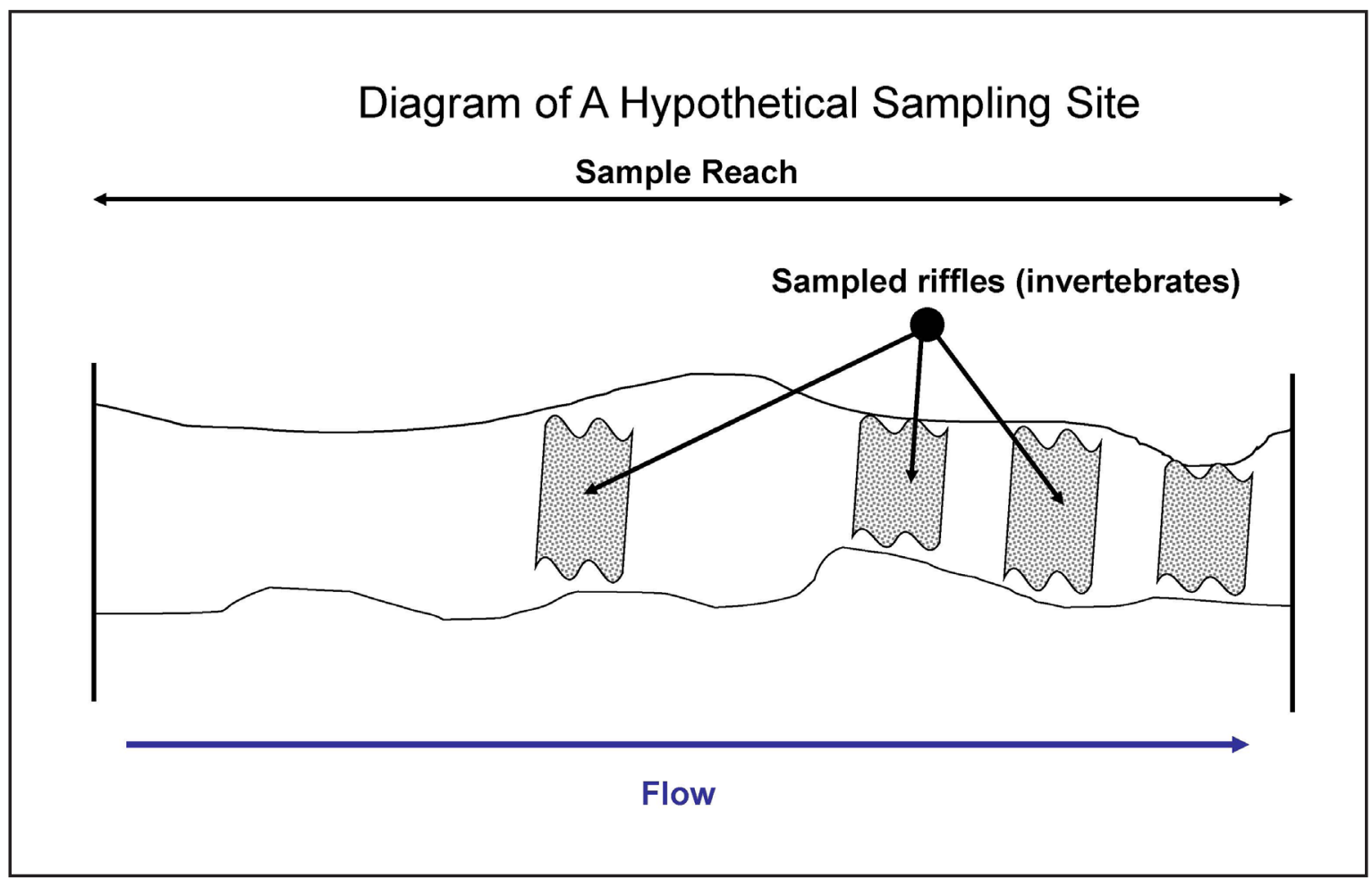

Figure 1. Riffle selection within a stream. 


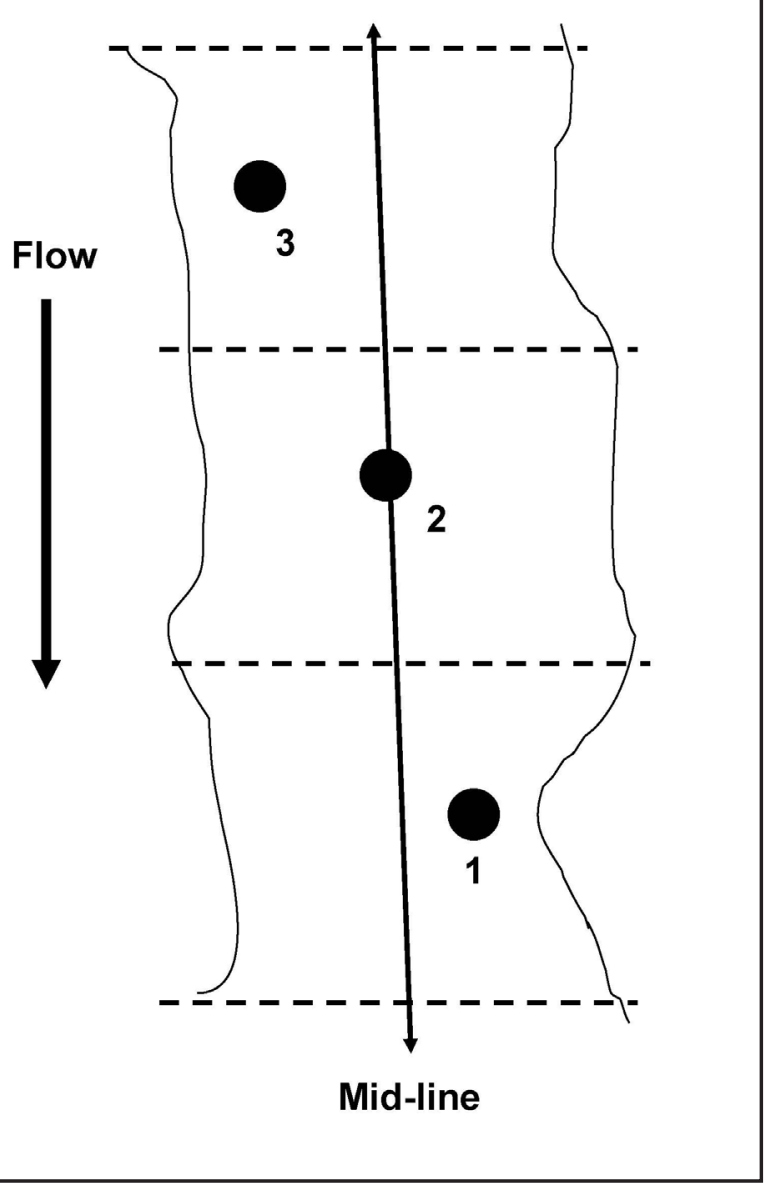

Figure 2. Placement of Surber samples within a single riffle.

\section{Sample Placement}

Placement of Surber samples within a given riffle appear to have been selected subjectively, or at best haphazardly, in the early monitoring protocol (Peterson et al. 1999). This provides an obvious opportunity to introduce bias into the sampling. To correct for this deficiency, this protocol ensures (after Bowles et al. 2007) that individual Surber samples will always be taken in an upstream direction in an a priori alternating and equally spaced sequence (left third, middle, and right third). This arrangement is illustrated in Figure 2. Sample sequence will be altered only if the original starting point presents a danger to the collector or if it is not accessible. Some riffles may be wider than long; in such cases, samples can be taken from left to right in equally spaced increments.

For Hester-Dendy samplers, the historical sampling locations used at HOME will continue to be used. Five samplers each will be placed in the upper and lower areas (Figure 3 ) with the individual samplers being placed no less than $1 \mathrm{~m}$ apart. Hester-Dendy samplers are prone to loss due to flooding in $\mathrm{Cub}$ Creek and having five sampling devices at each site is intended to offset such loss. Data from any samplers remaining at each site at the time of collection will be processed for analysis. Samplers are anchored to the bank with wire or attached to permanent structures as they are available in the stream channel.

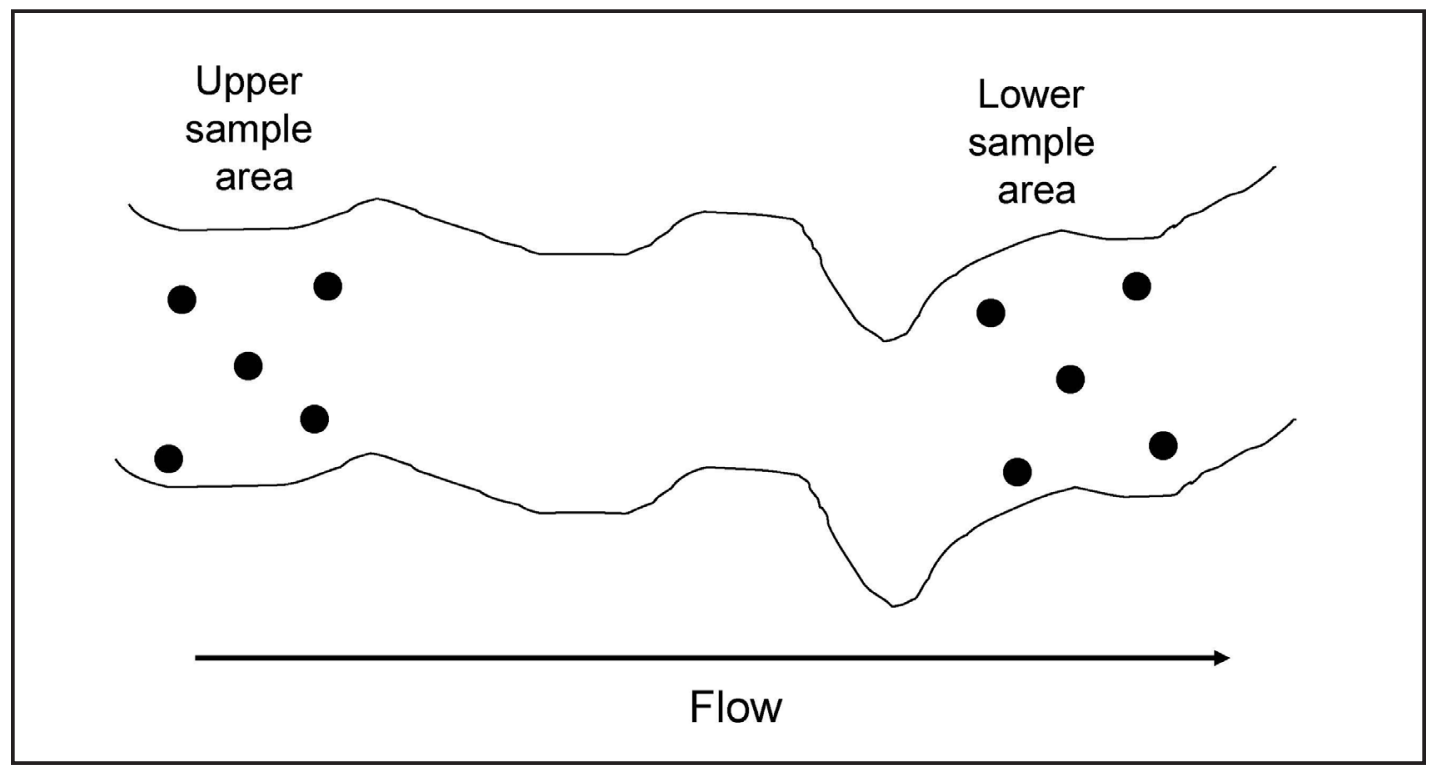

Figure 3. Placement of Hester-Dendy samplers in Cub Creek, HOME. 
Table 3. Revisit design for invertebrate monitoring in small streams at Heartland I\&M Network parks. X indicates a revisit.

\begin{tabular}{|c|c|c|c|c|c|c|c|c|c|c|c|c|c|}
\hline $\begin{array}{l}\text { Study } \\
\text { Parks }\end{array}$ & $\begin{array}{l}\text { Revisit } \\
\text { Notation }\end{array}$ & 2020 & 2021 & 2022 & 2023 & 2024 & 2025 & 2026 & 2027 & 2028 & 2029 & 2030 & 2031 \\
\hline $\begin{array}{l}\text { GWCA } \\
\text { PIPE } \\
\text { WICR }\end{array}$ & [1-2] & - & - & $X$ & - & - & $X$ & - & - & $X$ & - & - & $x$ \\
\hline $\begin{array}{l}\text { EFMO } \\
\text { HEHO } \\
\text { HOME }\end{array}$ & {$[1-2]$} & $X$ & - & - & $X$ & - & - & $X$ & - & - & $X$ & - & - \\
\hline $\begin{array}{l}\text { PERI } \\
\text { TAPR } \\
\text { HOSP }\end{array}$ & {$[1-2]$} & - & $X$ & - & - & $X$ & - & - & $X$ & - & - & $x$ & - \\
\hline
\end{tabular}

\section{Temporal Design}

The revisit design consists of a set of rotating panels for the network parks where each stream is sampled every three years (Table 3). The invertebrate communities of the small streams in network parks consist of a high diversity of species in various developmental stages. Therefore, temporal consistency in sample collection is essential to reducing the natural variability in invertebrate life cycles and community structure (Rabeni et al. 1997).

Boyle et al. (1990) recommended that sampling be done once in three of the four seasons (spring, summer, and fall), but gave no rationale for this approach. Peterson (1996) used data collected from a single year-1989- to assess the temporal variance in the metrics calculated. He reported two major findings: (1) for the same sample size, variance within a year was greater than variance within a single season (i.e., summer), and (2) variance decreased as sample size increased. Based on these findings, Peterson recommended that sampling should be done within a single season (i.e., summer) rather than over the entire year to decrease temporal variance, and that at least three samples be taken on different dates. In an independent assessment of Peterson (1996), Dr. Larissa Bailey (unpublished report) also recommended that sampling be conducted only once per year, within a specified time period. Dr. Bailey further specified optimal sampling periods for each prairie park based on invertebrate community stability and family richness metrics. Bailey recommended sampling in July, August, or September, depending upon the park.
Morrison and Bowles (2006) examined the complete dataset from 1988 to 2004 for all primary metrics included in this protocol. The mean values for each metric were comparable among all months sampled. Additionally, the estimates of standard error overlapped extensively, suggesting there is little difference among these metrics during the months sampled. To reduce costs and increase efficiency and robustness of the community metrics that are used, this protocol employs a single sampling event within the index periods shown in Table 2. Also, this sampling design controls for seasonality and intra-annual effects. Seasonal stream flow patterns must also be considered when choosing an index period for sampling, as flows become very low or streams dry entirely in some network streams in late summer. Although the Peterson et al. (1999) protocol specifies that three samples are to be taken each year, frequently only one or two were in fact collected due to low stream flows. The collection periods indicated above should ensure sufficient stream flows to allow effective sampling.

To the extent possible, temporal consistency should be maintained through successive years as well as between sample types. Samples from each stream should be collected within the shortest time frame possible (1-2 days) to minimize the effects of seasonal change. All efforts should be made to avoid collecting directly after a flood event or major disturbance. Samples must be collected only during baseflow conditions and a minimum of two weeks after flood waters recede to baseflow conditions. 


\section{Response Design}

\section{Types of Data Collected in the Field}

This monitoring program will collect benthic invertebrates from stream riffles as well as associated habitat and water quality data. Habitat features are major, often limiting, determinants of invertebrate community structure; accordingly, they are especially important for proper determination of biomonitoring results and assessment of ecological integrity (Barbour et al. 1999). Although habitat incorporates all aspects of physical and chemical constituents and their interactions, variables such as current velocity, substrate size, embeddedness, water chemistry, sediment deposition, and presence of filamentous algae and aquatic plants play key roles in the microhabitat structure and distribution of aquatic invertebrates (Allan 1995; Hauer and Lamberti 1996; Rosenberg et al. 2008). We propose to monitor all of the aforementioned habitat variables at our sampling sites.

Biological and environmental correlates of water quality and habitat structure compared across time are powerful tools for assessing disturbances related to natural and anthropogenic impacts on aquatic invertebrate communities, and they are useful for detecting change and elucidating patterns and trends in long-term data sets (Moulton et al. 2002). For example, as habitat conditions degrade (e.g., water quality decreases, embeddedness increases), degradation of the benthic invertebrate community is expected to follow. However, a cause and effect relationship between these variables and aquatic invertebrate community structure can be difficult to assess and analyze because there is often a broad response range among the resident species based on tolerance to disturbance (Norris and Georges 1993). Therefore, any association of community structure with these variables or their combinations must be interpreted cautiously and be based on real biological properties. These limitations withstanding, benthic community structure, when viewed in association with environmental variables, can be an effective indicator of ecosystem change (Reice and Wohlenberg 1993).

\section{Sampling Devices}

Choosing the appropriate sampling device is one of the most critical aspects of biomonitoring (Resh and McElray 1993). The physical characteristics of the stream determine the most appropriate device to use for sampling. Although a broad variety of sampling net types have been used to successfully sample stream riffles, the objectives of this protocol require continuity with the methods of Harris et al. (1991). Therefore, a Surber sampler (0.0929 $\mathrm{m}^{2}$ ) will continue to be the sampling device used to collect samples so the data will be comparable to the 1989 baseline data set and to other historical NPS sampling data. Harris et al. (1991) used Surber nets of differing mesh sizes depending on the stream sampled, but in this protocol we recommend using a single mesh size $(500 \mu \mathrm{m})$ for all streams sampled.

At HOME, benthic substrate is dominated by fine sands and current velocity is slow. Because of these constraints, Surber samplers would not be effective for sampling. Instead, we are using Hester-Dendy multiplate samplers that are placed in pools or slower-moving water (i.e., no riffles) to simulate stream habitats dominated by abundant woody debris. Samplers require water depth to be at least 25 $\mathrm{cm}$. These samplers are composed of nine $57.76-\mathrm{cm}^{2}$ hardboard plates separated by 3 plastic spacers and connected by a long eyebolt, ultimately providing $0.0929 \mathrm{~m}^{2}$ of surface area for invertebrate colonization. Although natural woody snags are superior to Hester-Dendy samplers for assessing invertebrate communities in soft-bottomed streams (Moulton et al. 2002), we continue using Hester-Dendy samplers to monitor invertebrate communities at HOME. The primary justification for using these samplers rather than collecting woody snags is that these sampling devices have been used historically at the park and the goal is to produce comparable data in future monitoring efforts. Illustrations of each sampling device are shown in SOP\#3.

\section{Number of Samples}

Three benthic samples will be randomly collected from each of three selected riffles, resulting in a total collection of nine separate samples per stream. This sampling approach provides an estimate of intraand inter-riffle variability. The process of collecting benthic samples is described in SOP\#3. Several studies have shown that three samples per riffle are sufficient to characterize the benthic invertebrate community with respect to calculation of metrics while accounting for variability (Canton and Chadwick 1988; Bowles 1989; Mathis 2001; Usrey and Hinsey 2006). 
For Cub Creek at HOME, five Hester-Dendy samplers will be deployed at each upstream and downstream sampling site for a total of 10 samples per sampling event. As previously stated above, this protocol recommends deploying five samplers because individual samplers are prone to loss from flooding. Data from any samplers remaining at each site at the time of collection will be processed for analysis.

\section{Suitability of Survey Design to Meet Study Objectives}

Monitoring objectives are integral to defining the sampling design. This sample design allows for assessing the integrity of invertebrate communities over time by measuring net change in certain community metrics. For assessing status and trend through time of invertebrate communities, the overall survey design was deemed suitable for several reasons:

1. Single habitat (riffle) sampling is appropriate for long-term monitoring of benthic invertebrates. Sampling multiple habitats provides more comprehensive information about the invertebrate fauna compared to single-habitat samples (Lenat and Barbour 1994; Moulton et al. 2002). However, comparability among sites is necessary for accurate bioassessments and invertebrates collected from the same habitat types among sites are more similar than invertebrates collected from multiple habitats within the same site (Parsons and Norris 1996; Rabeni et al. 1997). Indeed, Rabeni et al. (1997) showed metric sensitivity did not increase when comparing multiple versus single-habitat sampling in Missouri streams, and we contend this is true for other network streams. Therefore, single habitat sampling in riffle habitat is the focus of this protocol. For soft-bottomed streams such as Cub Creek at
HOME where the substrate consists primarily of sand, Hester-Dendy samplers are judged to be an acceptable means of assessing aquatic invertebrate communities.

2. Appropriate for all small streams in the network. The sampling design and methods described in this protocol are applicable to all small streams located in network parks. Furthermore, the data generated from this study design will be directly comparable to those of other regional (state and federal) invertebrate monitoring programs that employ similar methodologies and rely largely on percentage-based metrics (e.g., Barbour et al. 1999).

3. Easy to learn and use. Field procedures are easy to use and repeatable over time by different sampling crews trained in these procedures. Implementation does not require extensive time or costly equipment.

4. The sequence of sampling events and revisit design for the listed parks allows for the greatest amount of field work to be accomplished per year while minimizing cost. Because staff available for manning field crews is limited and there is a great distance among all network parks and travel costs associated with monitoring are high, this strategy allows cost-effective monitoring for stream sites in multiple network parks.

5. The selected approach to monitoring is advantageous over other approaches. The study design and methods selected for this protocol allow for an integration of community attributes and further allow us to characterize temporal changes and relative site quality. Additionally, our approach will allow us to correlate invertebrate community data with land use and habitat changes potentially arising from multiple stressors. 


\section{Field and Laboratory Methods}

\section{Field Season Preparations, Field Schedule, and Equipment Setup}

Procedures for field season preparations, including preparing a field sampling schedule and equipment setup, are described in SOP\#1 (Preparation for Field Sampling and Laboratory Processing). Team leaders will ensure that team members have read and understand the protocol and supporting SOPs prior to sampling and that all required equipment and supplies have been ordered and are in proper working condition. They should also check stream staff gages (http://water.usgs.gov) or contact park resource mangers to determine if sampling sites have recently flooded. The team leaders will prepare and maintain a field notebook detailing all sampling-related activities and staff participation during monitoring trips to ensure that trip reports are complete and accurate. Finally, the team leader should ensure that all required scientific collection permits have been obtained.

\section{Collecting Benthic Invertebrate Samples and Associated Habitat and Water Quality Data}

Procedures for collecting benthic invertebrate samples and documenting habitat data are presented in SOP\#3 (Sampling Invertebrates and Collecting Habitat Data), SOP\#4 (Documenting CORE 5 Water Quality Variables), and SOP\#5 (Measuring Stream Discharge). Work flow diagrams for collecting samples are shown in Figures 4 and 5.

Three invertebrate samples will be collected from each riffle at randomly selected sample points as described in SOP\#3. Samples will be collected with

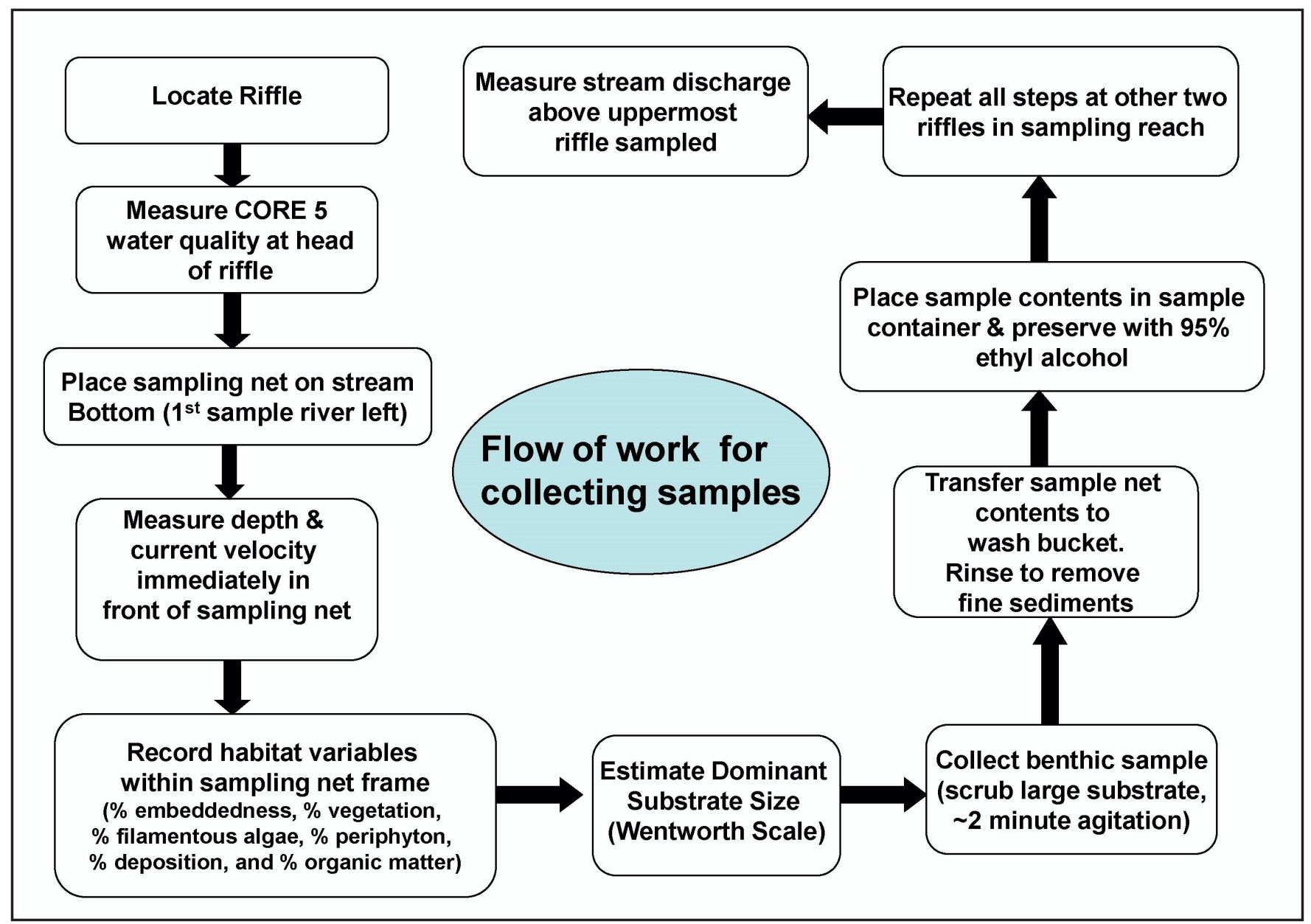

Figure 4. Flow of work diagram for collecting Surber samples. 


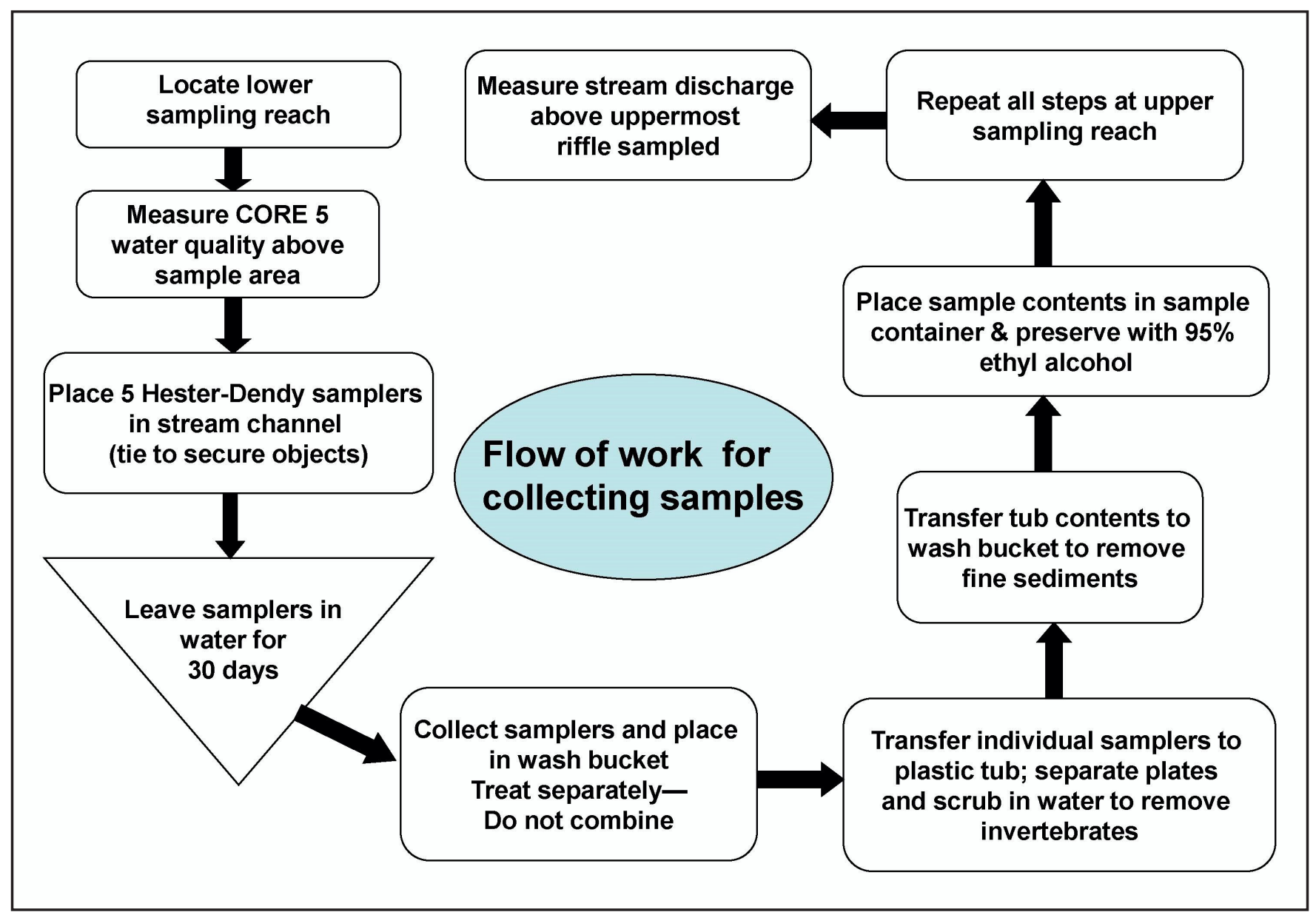

Figure 5. Flow of work diagram for collecting Hester-Dendy samples.

a Surber stream bottom sampler $(500-\mu \mathrm{m}$ mesh, $0.093 \mathrm{~m}^{2}$ ). Water flow (level) should not be over the top of the net in deep riffles to prevent invertebrates that are dislodged from the substrate from washing over the net and not being collected in the sample. Each discrete sample is collected while progressing in an upstream direction. Sampling procedures will be the same for each riffle sampled, and whenever possible, samples should be collected by the same person to limit variability in sampling techniques. For Homestead National Monument of America (HOME), five Hester-Dendy samplers will be deployed at each of two locations: one upstream and one downstream. Samplers are deployed for 30 days to allow for sufficient colonization by invertebrates prior to harvesting.

Habitat variables will include an assessment of depth and current velocity measurements collected concurrently and immediately in front of the sampler frame. Several additional qualitative measurements of habitat condition will be taken from the area delineated by the sampler frame after it is placed securely on the stream bottom and before disturbing the substrate. These variables include visual estimates of percent embeddedness of the substrate, percent periphyton, percent filamentous algae, and percent vegetation.

Standard classes for all percentage estimates will be as follows: $0=$ Absent $(0 \%), 1=$ Sparse $(<10 \%)$, $2=$ Moderate $(10-40 \%), 3=$ Heavy $(40-75 \%)$, and $4=$ Very Heavy $(>75 \%)$.

When the habitat variables have been recorded, substrate size is visually assessed. Substrate assessments provide a unique characterization of the streambed composition at the time sampling takes place. Therefore, dominant substrate size from the area within the sampling frame of the net is visually assessed based on the standard Wentworth scale (Wentworth 1922). The intent of the substrate assessment is to characterize the dominant substrate for individual samples and not to fully characterize all sediments present. This assessment will help us describe the prevailing microhabitat conditions that 
influence the structure of invertebrate communities and may help explain variability between sample points. Stream discharge will be measured at each site and preferably upstream of the sampling site after invertebrate collections have been completed. CORE 5 water quality parameters (temperature, dissolved oxygen, specific conductance, $\mathrm{pH}$, and turbidity) will be recorded for each stream using data loggers or sondes.

\section{Benthic Sample Processing and Specimen Identification}

Procedures for processing benthic samples and identifying specimens are described in SOP\#6 (Laboratory Processing and Identification of Invertebrates). Methods for preparing samples for sorting and subsampling generally follow those presented in Moulton et al. (2000). A list of the aquatic invertebrate taxa known or suspected to occur in network park small streams is provided in SOP\#8 (Data Analysis).

\section{Subsampling Benthic Samples}

The routine for subsampling benthic samples is presented in SOP\#6. The method of subsampling will involve the fixed fraction approach with $25 \%$ of each sample being sorted following thorough washing, agitation, sieving, and elutriation of the entire sample (Moulton et al. 2000). Additionally, a large and/or rare taxa component will be included where large or rare taxa that clearly are not in the sorted fraction are removed and stored in a separate vial for the purpose of reflecting accurate sample species richness estimates and calculating specific metrics such as EPT richness. A fixed-fraction subsampling routine was selected over a fixed-count routine because some of the metrics to be calculated from samples are related to specimen density that cannot be obtained with the latter method. Subsampled fraction debris will be subjected to quality assurance/quality control (QA/ QC) analysis (SOP\#6) and should be kept until QA/ $\mathrm{QC}$ is complete for that batch of samples and the program leader authorizes disposal of the debris.

\section{Sample Storage and Reference Collection}

Identified samples are stored in 4-dram glass vials with polycone caps and filled with $70 \%$ ethyl alcohol. Specimen vials will be labeled with the taxon name, date collected, park and site names/code, and name of identifier. Organisms will be retained for at least three years and stored at the NPS HTLN facilities located at Missouri State University, Springfield, MO.

A reference collection consisting of a few representative specimens of each taxon will be prepared and stored in properly labeled vials containing $70 \%$ ethyl alcohol. Regional or other taxonomist specialists should review the identifications for accuracy. This collection is intended to aid future identifications and for training new personnel. The reference collection will be stored at the NPS HTLN facilities located at Missouri State University, Springfield, MO.

\section{Post Season Procedures}

Procedures for the end of the sample season are found in SOP\#10 (Procedures and Equipment Storage after the Field Season) and are not further described here. Crew leaders will ensure all equipment is cleaned and properly stored and that all equipment is in working order prior to long-term storage. 


\section{Data Management}

Data management procedures are an important part of any long-term monitoring program because they provide data consistency, data security, and availability over time. Therefore, care must be taken to ensure that adequate time and personnel are available for accurate data recording, data entry and verification, and analysis. At the core of data management is the monitoring database organized by primary and ancillary data.

Data processing typically involves the following steps: data entry, data verification, data validation and backups/storage; see SOP\#7 (Data Management) for details on each step. Data entry consists of transferring field data from field sheets into a monitoring database using data entry forms. Data verification immediately follows data entry and involves checking the accuracy of computerized records against the original source, usually paper field records. Validation procedures seek to identify generic errors, such as missing, mismatched, or duplicate records, as well as logical errors specific to particular projects. Spatial validation of location coordinates can be accomplished using a Geographic Information System (GIS). Global Navigation Satellite System (GNSS) points are validated against high resolution imagery and/or LiDar for their general location.

\section{Overview of Database Design}

One tabular Microsoft Access database, henceforth referred to as the database, contains all data for the monitoring project. A generalized model of the invertebrate community database includes two primary tables for sampling events and locations. These two core tables contain general information pertaining to the field sampling occasion (the when and where of the sample). This includes information such as date and time, reach ID, and park/project codes. The invertebrate community tables serve as the organizing hub for invertebrate data. Other tables primarily address habitat or water quality conditions. The database also documents the protocol version and quality assurance and quality control results.

\section{Quality Assurance and Quality Control}

Quality Assurance (QA) includes all activities designed to ensure that data, products, or services meet specified requirements. Quality Assurance focuses on building in quality to prevent defects.
Quality Control (QC) includes procedures for checking whether data meet standards and annotating or qualifying data that do not (DeVivo 2016).

QA/QC procedures and design elements occur throughout data collection, processing, and reporting. The database design includes fields to document the completion and results of QA/QC procedures and assessments.

- The Inventory and Monitoring Division Data Base Standards (Frakes et al. 2015) document requires every datum to be unambiguously traceable to a specific version of a monitoring protocol, a quality assurance plan (QAP) where available, and suite of standard operating procedures (SOPs).

- The certification guidelines for I\&M data products (NPS 2016), and Minimum Implementation Standards for Network Projects v. 3.0 (Frakes and Kingston 2017) calls for every datum to have an associated QA/QC processing level (e.g., raw, provisional, certified).

- An annual operational review is required for all active monitoring protocols (Mitchell et al. 2018). Completion of an operational review, a summary of any flagged data, and a link to the review report are stored in the monitoring database.

\section{Metadata Procedures}

The Federal Geographic Data Committee (FGDC) now provides a range of options as guidance for metadata of spatial and non-spatial federal agency data. Most recommendations are variations of the ISO19115 standard, which is typically used for natural resource datasets. Creation of ISO metadata has been greatly facilitated by ESRI ArcGIS utilities that automatically generate spatial metadata. Once metadata are created, they should be saved in XML format following ISO metadata standards. Metadata are archived in the geodatabase and by Washington D.C. Area Support Office (WASO) I\&M Division in the Integrated Resource Management Applications Data Store (IRMA DataStore). Metadata are archived by WASO with the submission of the monitoring protocol. Metadata will be updated with each protocol revision. 


\section{Data Archival Procedures}

HTLN archives all spatial and non-spatial data (including tabular documents) on a weekly basis. Backups are incremental rather than mirrored so that files are never overwritten. Permanent data archives are created on a quarterly and annual basis and stored offsite in a bank safe box.

Like other monitoring databases/geodatabases, the aquatic invertebrate monitoring database is secured by file archives stored on the server. The databases are maintained under a directory called HTLNInvert under the heartlandcommon production drive. The database immediately below this directory is the production copy of the database. All backups are incremental rather than mirrored so that earlier versions are stored under this directory.

Annually, in fulfillment of the Data Analysis and Reporting Requirements (Gallo, K. memorandum dated 4/23/2018), the dataset will be uploaded to IRMA DataStore. The dataset is flagged as read only for all users except the Project Leader and Data Manager. 


\section{Data Summary, Analysis, and Reporting}

\section{Metric Selection and Community Indices}

Early biomonitoring programs tended to focus on one or two specific attributes or metrics of the community; the indicator species concept (Kremen 1992) is an example. Individual metrics generally are chosen based on the specific and predictable response of organisms to landscape changes. Additionally, they are sensitive to a range of factors that stress biological systems and are relatively easy to measure and interpret (Karr and Chu 1999). Barbour et al. (1999) lists and briefly describes many types of metrics used in assessing stream condition. However, individual metrics in themselves are often not adequate for assessing complex systems with cumulative impacts (Karr 1991).

In comparison, multimetric indices are designed to look at community structure through examination of multiple components of the invertebrate community and their level of change due to disturbance. Scores of individual metrics are normalized into a single integrated score, reducing the influence of one metric on the overall score and making results less ambiguous for resource managers. Bonada et al. (2006), in a comparative analysis of recent bioassessment approaches, showed that multimetric approaches rate among the best performers for 10 of 12 criteria they tested for discriminating among different kinds of human impact. Multimetric approaches are favored by most aquatic resource agencies in the United States because they are based on sound scientific rationale, they are simple to implement, and they are among the most sound for assessing invertebrate community structure (Lenz and Miller 1996; Bonada et al. 2006).

Peterson et al. (1999) concluded that invertebrate community structure could be adequately summarized by five biotic indices (i.e., total density; family biotic index; Ephemeroptera, Plecoptera and Trichoptera (EPT) richness; EPT/Chironomidae ratio; and the Shannon-Weiner Index). These indices were chosen because they represented independent estimates of change with minimal redundancy in the community aspects estimated by each metric (i.e., metrics were avoided if they appeared equally sensitive to the same environmental factors). This monitoring protocol retained most of those metrics to characterize invertebrate communities taking into account that metrics differ in their sensitivity to changes in different environmental variables. For example, some metrics may be more sensitive to changes in structural variables such as sediment grain size than to chemical and physical water quality variables (Bode and Novak 1995; Yoder and Rankin 1995). The exception is total density that Peterson et al. (1999) recommended for Hester-Dendy samples. Although total invertebrate density may decrease when communities are exposed to a stress such as water pollution or habitat alteration (Resh and Grodhaus 1983; Plafkin et al. 1989), it can also be notoriously variable under normal conditions (Chutter 1972; Kroger 1972) and provide misleading results. Taxa richness and genus evenness were included as additional measures of community integrity based in part on the recommendation of Rabeni et al. (1997). Procedures for calculating these metrics are shown in SOP\#8 (Data Analysis). Summary indices and variables will provide information to park managers on the status of stream invertebrate communities.

\section{EPT Richness}

Ephemeroptera, Plecoptera, and Trichoptera (EPT) richness is the number of genera from these three orders represented in a sample. Members of these three insect orders are among the most ecologically sensitive taxa in streams and are considered excellent indicators of water quality (Resh and Jackson 1993; Resh and McElray 1993).

\section{EPT Ratio (R)}

The ratio of EPT abundance (numbers of individuals) to Chironomidae (C) abundance ( $\mathrm{R}=\mathrm{EPT} /[\mathrm{EPT}$ $+\mathrm{C}])$ has also been used as a stream water quality indicator (Resh and Grodhaus 1983). It is calculated only for replicate Surber samples. In general, EPT taxa are relatively pollution intolerant, whereas Chironomidae are generally pollution tolerant. Thus, higher values indicate better stream water quality.

\section{Taxa Richness}

Taxa richness is simply the sum of the number of taxa represented in a sample replicate. Richness can be a useful criterion to describe the biological quality of a stream (Resh and Grodhaus 1983). Low richness may indicate that a stream has been subjected to one or 
more stressors. This protocol uses both family level and genus richness.

\section{Taxa Diversity}

Diversity is a measure of how the total number of individuals in a sample are distributed among the total species in the sample. Maximum diversity occurs in a community when the number of individuals is distributed as evenly as possible among species (Pielou 1966). High diversity indicates better stream quality (Resh and Jackson 1993). This protocol uses the Shannon Index (or Shannon-Wiener diversity index; $\mathrm{H}^{\prime}$ ) to estimate taxa diversity.

\section{Genus Evenness}

This metric, also known as Shannon's Evenness Index, is a measure of how evenly the total number of individuals in a sample are distributed among the genera. Lower evenness indicates that a stream may have been subjected to disturbance and it is being populated by fewer and pollution-tolerant genera. This index is calculated using the values of the Shannon Diversity index.

\section{Biotic Indices}

Biotic indices are commonly used as indicators of water quality (Resh and Jackson 1993; Resh and McElray 1993). In fact, Jones et al. (1981), simultaneously measured invertebrate community structure and water quality variables in Missouri Ozark streams and found biotic indices to be more sensitive and less variable than diversity indices for discriminating differences in stream water quality. The Hilsenhoff biotic index (HBI) uses taxa specific (e.g., family, genus) pollution tolerance values (Hilsenhoff 1982, 1988; Lenat 1993) to calculate index scores, which can then be related to stream water quality. This protocol uses genus level tolerance values allowing for a better estimate of community tolerance.

The metrics listed above are generally considered sufficiently sensitive to detect a variety of potential pollution problems in network streams. Some of the potential disturbances and the metrics that can be used to detect them include the following (after Doisy and Rabeni, 1999).

- Gross organic pollution - Hilsenhoff (1982) listed all four of the selected metrics as indicators of gross organic pollution.
- Agriculturally developed catchments - Ephemeroptera and Plecoptera have shown reductions in abundance or richness with these catchments (Quinn and Hickey 1990; Lenat and Crawford 1994).

- Increases in acidity - Taxa richness, EPT taxa, and Shannon Diversity Index typically decrease in response to increasing acidity (Hildrew et al. 1984; MacKay and Kersey 1985). Mayflies are especially sensitive to low $\mathrm{pH}$ (Peterson et al. 1985).

- Effects of logging and clear cutting - Stone and Wallace (1998) found that the North Carolina Biotic Index (NCBI, a modification of the Biotic Index; Lenat 1993) was the most sensitive to this type of disturbance.

- Heavy metal pollution - Taxa richness and EPT richness (Winner et al. 1980; Chadwick et al. 1986) have been shown to decrease in response to this type of pollution. However, further research indicates that mayflies may decrease in richness and abundance while caddisflies increase under these conditions, resulting in static EPT richness. If no difference in the EPT is found, analysis of the richness and percent composition of mayfly taxa should be performed (Doisy and Rabeni 1999).

- Insecticides - Wallace et al. (1996) found that both the EPT index and the NCBI easily detected disturbances to a stream treated with certain insecticides.

Water quality for each site can be inferred using these metrics. For metrics that decrease with increasing level of disturbance, higher metric values indicate higher water quality. For metrics that increase with increasing level of disturbance, lower metric values suggest higher water quality.

\section{Data Analysis}

In determining the appropriate statistical approaches for this monitoring protocol, it is important to take into account the primary audience of the various reports that will be produced. This audience will consist of park resource managers, park superintendents, and other park staff. Park resource managers and staff may not have an in-depth background in statistical methods, and park superintendents may have limited time to devote to such reports. Additionally, protocols such as this may provide a large amount of data on many different types of variables. 
Thus, it is important, to the extent possible, that core data analyses and presentation methods provide a standard format for evaluation of numerous variables, are relatively straightforward to interpret, can be quickly updated whenever additional data become available, and can be used for many different types of indicators, whether univariate or multivariate. In addition, the type and magnitude of variability or uncertainty associated with the results should be easily discernible, and a threshold for potential management action will ideally be indicated.

There are three main statistical approaches that could be employed with data from long-term monitoring projects such as this: (1) hypotheses testing, (2) parameter estimation, and (3) application of Bayesian methods.

\section{Bayesian Methods}

When analyzing ecological data, statisticians predominantly employ frequentist methods, and thus many resource managers are not familiar with the interpretation of Bayesian approaches. Bayesian methods are not widely used because they are often difficult to apply, and many researchers are not comfortable specifying subjective degrees of belief in their hypotheses (Utts 1988; Hoenig and Heisey 2001). Therefore, a Bayesian approach is not advocated as the main method of data analysis in this protocol.

\section{Hypothesis Testing}

Most hypothesis testing approaches involve a null hypothesis of no difference or no change. The problem with such approach is that the hypothesis under test is thus trivial (Cherry 1998; Johnson 1999; Anderson et al. 2000, 2001). No populations or communities will be exactly the same at different times. Therefore, the primary interest of this protocol is the magnitude of change rather than change per $s e$, and whether it represents something biologically important. Null hypothesis significance testing relies heavily on $P$-values, and results primarily in yes/no decisions (reject or fail to reject the null hypothesis). $P$-values are strongly influenced by sample size, however, and one may, with a large enough sample size, obtain a statistically significant result that is not biologically important. Alternatively, with a small sample size, one may determine that a biologically important result is not statistically significant (Yoccoz 1991). Thus, traditional null hypothesis testing places the emphasis on the $P$-value (which is dependent on sample size) and rejection of the null hypothesis, whereas we should be more concerned whether the data support our scientific hypotheses and are practically (i.e., biologically) significant (Kirk 1996; Hoenig and Heisey 2001).

\section{Parameter Estimation}

This approach provides more information than hypothesis testing, is more straightforward to interpret, and is easier to compute (e.g., Steidl et al. 1997; Gerard et al. 1998; Johnson 1999; Anderson et al. 2000, 2001; Colegrave and Ruxton 2003; Nakagawa and Foster 2004). Parameter estimation emphasizes the magnitude of effects and the biological significance of the results, rather than making binary decisions (Shaver 1993; Stoehr 1999). Moreover, trend studies should focus on description of trends and their uncertainty, rather than hypothesis testing (Olsen et al. 1997). Thus, most of the data analyzed under this protocol will take the form of parameter estimation rather than null hypothesis significance testing.

\section{Control Charts}

We will also employ control charts in data organization and analysis. Control charts represent a basic summary for almost any data set, a sort of quick look for busy managers to determine which variables are in the greatest need of more in-depth analyses or management action (Morrison 2008). Developed for industrial applications, control charts indicate when a system is going out of control by plotting through time some measure of a stochastic process with reference to its expected value (e.g., Beauregard et al. 1992; Gyrna 2001; Montgomery 2001). Control charts may be univariate or multivariate, and can represent many different types of variables. They have been applied to ecological data (McBean and Rovers 1998; Manly 2001), including fish communities (Pettersson 1998; Anderson and Thompson 2004) and natural resources within the I\&M program (Atkinson et al. 2003). Control charts contain upper and lower control limits specifying thresholds beyond which variability in the indicator reveals a biologically important change is occurring and warns that management may need to act. Control limits can be set to any desired level. 
Multivariate control charts may also be constructed, and although some of the above-mentioned texts describe multivariate control charts (using the Hotelling $\mathrm{T}^{2}$ statistic), this approach is only practical for a small number of variables, and assumes a multivariate normal distribution. In general, species abundances are not distributed as multivariate normal (Taylor 1961), and traditional multivariate procedures are frequently not robust to violations of this assumption (Mardia 1971; Olson 1974). A new type of multivariate control chart has recently been described for use with complex ecological communities and a software application entitled ControlChart.exe is available for constructing these types of multivariate control charts (see Anderson and Thompson 2004). Multivariate temporal autocorrelation will violate the assumption of stochasticity upon which this method is based. However, it is important to test for temporal autocorrelation using Mantel correlograms prior to using this method. This new multivariate control chart appears to have promise but has not been widely applied nor thoroughly evaluated. Further evaluation of this method is warranted before being applied to the data of this protocol.

\section{Power Analysis}

A formal power analysis for this protocol was not conducted for three reasons. (1) The primary purpose of conducting a prospective power analysis is to determine whether the proposed sample size is adequate. There already exist a number of studies indicating that three samples per riffle is an appropriate number for calculation of the proposed metrics (see Number of Samples under the Sample Design Section). Because the sample size described above is driven primarily by budget, an increase in the number of riffles sampled per reach or number of reaches could not be justified regardless of the result of any power analysis. Furthermore, in many analyses sample size will equate with number of years and become more powerful over time. (2) Statistical power is dependent upon the hypothesis under test and the statistical test used. Over the course of this long-term monitoring program, we will be interested in many different questions and could potentially evaluate a number of different hypotheses. Thus, there is no single power relevant to the overall protocol. Estimating power at this point in the context of such a long-term, multifaceted monitoring program could be potentially misleading as the test this power is based upon may rarely (or never) actually be employed. (3) Most of our data analyses will take the form of parameter estimation rather than null hypothesis significance testing. When estimating parameters, there is no associated statistical power. In general, statistical power analyses are frequently misused and misinterpreted in ecological contexts (Morrison 2007), and alternative approaches to evaluating the degree of uncertainty associated with our data will be evaluated and used when applicable.

\section{Other Statistical Tests}

Although our primary approach to organizing and analyzing data will consist of multimetric indices, we do not entirely rule out the use of any statistical methods at this time. Because of the nature of this long-term monitoring program, other approaches may be appropriate at different points in time. Depending upon the needs of the resource managers and questions of interest, a hypothesis testing framework may be employed. Because data from studies of aquatic insects is often not normally distributed, non-parametric approaches may be necessary. For example, if it is desirable to test for differences between riffles, non-parametric tests should be used (e.g., Kruskal-Wallace Test, Friedman's Test, or Cochran's Q test). Of course, normality of the data will be evaluated prior to any tests, and transformations may be performed if useful prior to tests requiring normal distributions. These approaches and others are described in SOP\#8.

\section{Reporting}

Annual reporting requirements include an informal trip report, and an operational review report. The updates may be in the form of a web article or data visualizer. Trend reports are updated every four years (2 sampling cycles). Trend reports explore correlations among the data over time. Trend reports are published as Natural Resource Reports in the NPS Natural Resource Publication Series and uploaded to the Integrated Resource Management Applications Data Store (IRMA DataStore) or published in peer reviewed scientific literature. Refer to SOP\#9 (Data Reporting) for details on reporting. 


\section{Personnel Requirements and Training}

\section{Roles and Responsibilities}

The project manager is the aquatic program leader for the HTLN and this person bears responsibility for implementing this monitoring protocol. Because consistency is essential to implementation of the protocol, the project manager or HTLN aquatic ecologist will lead field data collection efforts unless technicians have several years of experience collecting the data related to this protocol as determined by the project manager. The project manager will oversee all laboratory work including all QA/QC requirements.

The data management aspect of the monitoring effort is the shared responsibility of the project manager and the data manager. Typically, the project manager is responsible for data collection, data entry, data verification and validation, data summary, analysis, and reporting. The data manager is responsible for data archiving, data security, dissemination, and database design. The data manager, in collaboration with the project manager, also develops data entry forms and other database features as part of quality assurance and automates report generation. The data manager is ultimately responsible to ensure that adequate QA/QC procedures are built into the database management system and appropriate data handling procedures followed. Technicians will be responsible for field collection and laboratory processing, equipment maintenance, purchasing of supplies, and sample storage. At least one technician with taxonomic experience will be responsible for the identification of specimens to the genus level.

\section{Qualifications and Training}

Training is an essential component for collection of credible data. Training for consistency and accuracy should be emphasized for both the field and laboratory aspects of the protocol. SOP\#2 (Training for Field Sampling and Laboratory Processing) describes the training requirements for new technicians. The project manager should oversee this training and ensure that each technician is adequately prepared to collect data. Taxonomic identifications may be performed by a technician with several years of experience, but initial identifications should be checked by expert taxonomists. 


\section{Operational Requirements}

\section{Field Schedule}

Streams scheduled for sampling, as listed in the revisit schedule (Table 3 ), should be sampled once during the appropriate index period (Table 2). Samples should be collected within the shortest time frame possible. At a minimum, two people are required to complete the field sampling portion of the protocol; however, three people make the process much more efficient. Only one site can be sampled per day under normal circumstances.

\section{Facility and Equipment Requirements}

Field and lab equipment listed in SOP\#1 (Preparation for Field Sampling and Laboratory Processing) are for only one sampling crew. Beyond normal office and equipment storage space, facility needs include access to a wet laboratory. Additional equipment requirements include maintenance and/or replacement of equipment shared among multiple projects (e.g., GNSS units, cameras, vehicles, computer server). Network vehicles are shared and fuel/maintenance costs are incurred at the network level.

\section{Budget Considerations}

Approximately one full work day plus travel is required to complete sampling for each sampling park. For parks having multiple streams, it is practical to sample all those streams in a single day. Personnel expenses for fieldwork are based on a minium crew of two people, although three are optimum. The crew will consist of a professional aquatic ecologist or fisheries biologist to oversee and coordinate fieldwork and data collection and one or morebiological science technicians. Field costs will vary from year to year depending on the skill level, size of the crew, and parks to be sampled (number and distance from work domain). Laboratory processing time per benthic sample, including sorting, identification, counting, and entry into the database, will require approximately 6 hours per sample.

Data management personnel expenses include staff time of biological science technicians, project manager, and data manager. The project leader also invests time in preparation for field trips (two or more days) and data evaluation and reporting. These steps can include a month or more of the project leader's time per report, in addition to peer reviewer's time. Additional shared support staff include the quantitative ecologist and geographic information specialist. 


\section{Procedures for Protocol Revision}

Revisions to both the protocol narrative and to specific standard operating procedures (SOPs) are to be expected. Careful documentation of changes to the protocol and a library of previous protocol versions are essential for maintaining consistency in data collection and for appropriate treatment of the data during data summary and analysis. The steps for changing the protocol (either the protocol narrative or the SOPs) are outlined in SOP\#11 (Revising the Protocol). 


\section{Literature Cited}

Allan, J. D. 1995. Stream ecology, structure and function of running waters. Chapman \& Hall, New York, NY.

Anderson, D. R., K. P. Burnham, and W. L. Thompson. 2000. Null hypothesis testing: problems, prevalence, and an alternative. Journal of Wildlife Management 64:912-923.

Anderson, D. R., W. A. Link, D. H. Johnson, and K. P. Burnham. 2001. Suggestions for presenting the results of data analyses. Journal of Wildlife Management 65:373-378.

Anderson, M. J., and A. A. Thompson. 2004. Multivariate control charts for ecological and environmental monitoring. Ecological Applications 14:1921-1935.

Atkinson, A. J., R. N. Fisher, C. J. Rochester, and C. W. Brown. 2003. Sampling design optimization and establishment of baselines for herptofauna arrays at the Point Loma Ecological Reserve. United States Geological Survey, Western Ecological Research Center, Sacramento, CA.

Barbour, M. T., J. Gerritsen, B. D. Snyder, and J. B. Stribling. 1999. Rapid bioassessment protocols for use in streams and wadeable rivers: Periphyton, benthic macroinvertebrate, and fish: $2^{\text {nd }}$ edition. EPA 841-B-99-002, U.S. Environmental Protection Agency, Washington, DC.

Bazata, K. 2005. Nebraska stream classification using fish, macroinvertebrates, habitat, and, chemistry evaluations from R-EMAP data, 1997-2001. Project Report, Nebraska Department of Environmental Quality, Lincoln, NE.

Beauregard, M. R., R. J. Mikulak, and B. A. Olson. 1992. A practical guide to statistical quality improvement: Opening up the statistical toolbox. Van Nostrand Reinhold, New York, NY.

Bode, R. W., and M. A. Novak. 1995. Development and application of biological impairment criteria for rivers and streams in New York State. Pages 97-107 in W. S. Davies and T. P. Simon, editors. Biological Assessment and Criteria. Lewis Publishers, Boca Raton, FL.

Bowles, D. E. 1989. Life history and variability in secondary production estimates for Corydalus cornutus (Megaloptera: Corydalidae) in an Ozark stream. Journal of Agricultural Entomology 7:61-70.

Bowles, D. E. 2013a. Aquatic invertebrate monitoring at George Washington Carver National Monument, 2005-2010 status report. Natural Resource Data Series NPS/HTLN/NRDS2013/497. National Park Service, Fort Collins, CO.

Bowles D. E. 2013b. Aquatic invertebrate monitoring at Wilson's Creek National Battlefield: 19962010 status and trend report. Natural Resource Technical Report NPS/HTLN/NRTR2013/754. National Park Service, Fort Collins, CO.

Bowles, D. E. 2015. Aquatic invertebrate monitoring at Homestead National Monument of America, 1996-2014. National Park Service, Heartland Inventory and Monitoring Network, Republic, MO.

Bowles, D. E., and M. K. Clark. 2012. Aquatic invertebrate monitoring at Homestead National Monument of America: 1996-2011 trend report. Natural Resource Technical Report NPS/HTLN/NRTR-2012/612. National Park Service, Fort Collins, CO.

Bowles, D. E., J. T. Cribbs, and J. A. Hinsey. 2016. Aquatic invertebrate monitoring at Tallgrass Prairie National Preserve, 2009-2015. Natural Resource Data Series NPS/TAPR/NRDS2016/1062. National Park Service, Fort Collins, CO.

Bowles, D. E., J. T. Cribbs, and J. A. Hinsey. 2017. Aquatic invertebrate monitoring at Hot Springs National Park, 2009-2015. Natural Resource Data Series NPS/HTLN/NRDS-2017/1126. National Park Service, Fort Collins, CO. 
Bowles, D. E., J. T. Cribbs, and J. A. Hinsey. 2018. Aquatic invertebrate monitoring at Pea Ridge National Military Park, 2009-2015. Natural Resource Data Series NPS/HTLN/NRDS2018/1146. National Park Service, Fort Collins, CO.

Bowles D. E., H. R. Dodd, and J. A. Luraas. 2010a. Aquatic invertebrate monitoring at Effigy Mounds National Monument, 2008. Natural Resource Data Series NPS/HTLN/NRDS2010/071. National Park Service, Fort Collins, CO.

Bowles D. E., H. R. Dodd, and J. A. Luraas. 2010b. Aquatic invertebrate monitoring at Herbert Hoover National Historic Site, 2008. Natural Resource Data Series NPS/HTLN/NRDS2010/053. National Park Service, Fort Collins, CO.

Bowles, D. E., J. A. Luraas, and J. T. Cribbs. 2013. Aquatic invertebrate monitoring at Pipestone National Monument: 1996-2010 status and trend report. Natural Resource Technical Report NPS/HTLN/NRTR—2013/824. National Park Service, Fort Collins, CO.

Bowles, D. E., J. A. Luraas, L. W. Morrison, H. R. Dodd, M. H. Williams, G. A. Rowell, M. D. DeBacker, J. A. Hinsey, F. D. Usrey, J. L. Haack. 2007. Protocol for monitoring aquatic invertebrates at Ozark National Scenic Riverways, Missouri, and Buffalo National River, Arkansas. Natural Resource Report NPS/ HTLN/NRR-2007/009. National Park Service, Fort Collins, CO.

Bowles, D. E., M. H. Williams, H. R. Dodd, L. W. Morrison, J. A. Hinsey, C. E. Ciak, G. A. Rowell, M. D. DeBacker, and J. L. Haack. 2008. Monitoring protocol for aquatic invertebrates of small streams in the Heartland Inventory \& Monitoring Network. Natural Resource Report NPS/HTLN/NRR—2008/042. National Park Service, Fort Collins, CO.

Boyle, T. P., M. A. Harris, and B. C. Kondratieff. 1990. Manual for implementation and development of aquatic resource inventory and monitoring methodology in prairie parks. U.S Department of the Interior, National Park Service, Water Resources Division, Fort Collins, CO.
Canton, S. P., and J. W. Chadwick. 1988. Variability in benthic invertebrate density estimates from stream samples. Journal of Freshwater Ecology 4:291-297.

Chadwick, J. W., S. P. Canton, and R. L. Dent. 1986. Recovery of benthic invertebrate communities in Silver Bow Creek, Montana, following improved metal mine wastewater treatment. Water, Air, and Soil Pollution 28:427-438.

Cherry, S. 1998. Statistical tests in publications of The Wildlife Society. Wildlife Society Bulletin 26:947-953.

Chutter, F. M. 1972. A reappraisal of Needham and Usinger's data on the variability of a stream fauna when sampled with a Surber sampler. Limnology and Oceanography 17:139-141.

Colegrave, N., and G. D. Ruxton. 2003. Confidence intervals are a more useful complement to nonsignificant tests than are power calculations. Behavioral Ecology 14:446-450.

DeBacker, M. D., C. C. Young (editor), P. Adams., L. Morrison, D. Peitz, G. A. Rowell, M. Williams, and D. Bowles. 2005. Heartland Inventory and Monitoring and Prairie Cluster Prototype Monitoring Program vital signs monitoring plan. U.S. National Park Service, Heartland I\&M Network and Prairie Cluster Prototype Monitoring Program, Wilson's Creek National Battlefield, Republic, MO.

DeVivo, J. 2016. DRAFT quality management plan for the National Park Service Inventory \& Monitoring Program: Guidance for vital signs monitoring protocols (distributed by K. Gallo email 8/19/2016).

Dodds, W. K., K. Gido, M. R.Whiles, K. M. Fritz, and M. J. Matthews. 2004. Life on the edge: the ecology of Great Plains prairie streams. BioScience 54:205-216.

Doisy, K. E., and C. F. Rabeni. 1999. Draft biological monitoring program for the Ozark National Scenic Riverways. Missouri Cooperative Fish and Wildlife Research Unit, University of Missouri, Columbia, MO. 
Flotemersch, J. E., J. B. Stribling, and M. J. Paul. 2006. Concepts and approaches for the bioassessment of non-wadeable streams and rivers. EPA 600-R-06-127. US Environmental Protection Agency, Cincinnati, OH.

Foreman, K. L. 2007. Water quality monitoring in the Hoover Creek watershed 2004-2006. Iowa Geological Survey Technical Information Series 53. Iowa Department of Natural Resources, Des Moines, IA.

Frakes, B., and S. Kingston. 2017. Minimum implementation standards for network projects v.3.0. National Park Service. Last accessed 5/23/2018: https://irma.nps.gov/DataStore/ DownloadFile/588637.

Frakes, B., S. Kingston, and M. Beer. 2015. Inventory and Monitoring Division database standards: September 11, 2015. Natural Resource Report NPS/NRSS/NRR_-2015/1035. National Park Service, Fort Collins, CO.

Gallo, K. 2018. Data analysis and reporting requirements memorandum dated 4/23/2018. Available at https://irma.nps.gov/DataStore/ DownloadFile/600325. Last accessed 5/23/2018.

Gebler, J. B. 2004. Mesoscale spatial variability of selected aquatic invertebrate community metrics from a minimally impaired stream segment. Freshwater Science 23:616-633.

Genet, J., and J. Chirhart. 2004. Development of a macroinvertebrate index of biological integrity (MIBI) for rivers and streams of the Upper Mississippi River Basin. Minnesota Pollution Control Agency Biological Monitoring Program, St. Paul, MN.

Gerard, P. D., D. R. Smith, and G. Weerakkody. 1998. Limits of retrospective power analysis. Journal of Wildlife Management 62:801-807.

Gregg, D. D., and J. D. Stednick. 2007. Variability in measures of macroinvertebrate community structure by stream reach and stream class. Journal of the American Water Resources Association 36:95-103.

Gyrna, F. M. 2001. Quality planning and analysis: From product development through use. McGraw-Hill Irwin, New York, NY.
Hall, D. L., B. S. Bergthold, and R. W. Sites. 2003. The influence of adjacent land use on macroinvertebrate communities of prairie streams in Missouri. Journal of Freshwater Ecology 18:55-68.

Harris, M. A., B. C. Kondratieff, and T. P. Boyle. 1991. Macroinvertebrate assemblages and water quality in six national park units in the Great Plains. National Park Service, Water Resources Division, Fort Collins, CO.

Harris, M. A., B. C. Kondratieff, and T. P. Boyle. 1999. Macroinvertebrate community structure of three prairie streams. Journal of the Kansas Entomological Society 72:402-425.

Hauer, F. R., and G. A. Lamberti (editors). 1996. Methods in stream ecology. Academic Press, Inc., New York, NY.

Herbst, D. B., and E. L. Silldorff. 2006. Comparison of the performance of different bioassessment methods: similar evaluations of biotic integrity from separate programs and procedures. Journal of the North American Benthological Society 25:513-530.

Hildrew, A. G., C. R. Townsend, J. Francis, and K. Finch. 1984. Cellulolytic decomposition in streams of contrasting $\mathrm{pH}$ and its relationship with invertebrate community structure. Freshwater Biology 14:323-328.

Hilsenhoff, W. L 1982. Using a biotic index to evaluate water quality in streams. Wisconsin Department of Natural Resources Technical Bulletin. No. 132.

Hilsenhoff, W. L. 1988. Rapid field assessment of organic pollution with a family-level biotic index. Journal of North American Benthological Society 7:65-68.

Hoenig, J. M., and D. M. Heisey. 2001. The abuse of power: the pervasive fallacy of power calculations for data analysis. The American Statistician 55:19-24.

Jones, J. R., B. H. Tracy, J. L. Sebaugh, D. H. Hazelwood, and M. M. Smart. 1981. Biotic index tested for ability to assess water quality of Missouri Ozark streams. Transactions of the American Fisheries Society 110:627-637. 
Johnson, D. H. 1999. The insignificance of statistical significance testing. Journal of Wildlife Management 63:763-772.

Kansas Department of Health and Environment (KDHE). 2000. Division of Environment, quality management plan, part III. Stream biological monitoring program, quality assurance management plan. Bureau of Environmental Field Services, Technical Services Section, Topeka, KS.

Karr, J. R. 1991. Biological integrity: a long-neglected aspect of water resource management. Ecological Applications 1:66-84.

Karr, J. R., and W. E. Chu. 1999. Restoring life in running waters: better biological monitoring. Island Press, Washington, DC.

Kirk, R. E. 1996. Practical significance: A concept whose time has come. Educational and Psychological Measurement 56:746-759.

Kroger, R. L. 1972. Underestimation of standing crop by the Surber sampler. Limnology and Oceanography 17:475-478.

Lazorchak, J. M., Klemm, D. J., and D. V. Peck. 1998. Environmental monitoring and assessment program-surface waters: field operations and methods for measuring the ecological condition of wadeable streams. EPA/620/R-94/004F, U.S. Environmental Protection Agency, Washington, DC.

Lenat, D. R. 1993. A biotic index for the southeastern United States: Derivation and list of tolerance values, with criteria for assigning waterquality ratings. Journal of the North American Benthological Society 7:222-223.

Lenat, D. R., and M. T. Barbour. 1994. Using benthic macroinvertebrate community structure for rapid, cost effective, water quality monitoring: Rapid bioassessment. Pages 171-186 in S. L. Loeb and A. Spacie, editors. Biological monitoring of aquatic systems. Lewis Publishers, Boca Raton, FL.

Lenat, D. R., and J. K. Crawford. 1994. Effects of land use on water quality and aquatic biota of three North Carolina Piedmont Streams. Hydrobiologia 294:185-199.
Mackay, R. J., and K. E. Kersey. 1985. A preliminary study of aquatic insect communities and leaf decomposition in acid streams near Dorset, Ontario. Hydrobiologia 122:3-11.

Manly, B. F. J. 2001. Statistics for environmental science and management. Chapman \& Hall/ CRC, Boca Raton, FL.

Mardia, K. V. 1971. The effect of nonnormality on some multivariate tests and robustness to nonnormality in the linear model. Biometrika 58:105-121.

Mathis, M. L. 2001. Development of a multi-metric system for biological water-quality monitoring for the Buffalo National River, University of Central Arkansas, Conway, AR [on-file at HTLN].

McBean, E. A. and F. A. Rovers. 1998. Statistical procedures for analysis of environmental monitoring data and risk assessment. Prentice Hall PTR, Upper Saddle River, NJ.

Minnesota Pollution control Agency (MPCA). 2018 2018 Minnesota water quality: surface water section (abbreviated narrative report), report to the Congress of the United States water years 2016-2017. St. Paul, MN.

Mitchell, B., A. Chung-MacCoubrey, J. Comiskey, L. Garrett, M. MacCluskie, B. Moore, T. Philippi, G. Sanders, and J. P. Schmit. 2018. Inventory and Monitoring Division protocol review guidance. Natural Resource Report NPS/NRSS/IMD/ NRR-2018/1644. National Park Service, Fort Collins, CO.

Montgomery, D. C. 2001. Introduction to statistical quality control. John Wiley \& Sons, Inc, New York, NY.

Morin, A., J. Stephenson, J. Strike, and A. G. Solimini. 2004. Sieve retention probabilities of steam invertebrates. Journal of the North American Benthological Society 23:383-391.

Morrison, L. W. 2007. Assessing the reliability of ecological monitoring data: Power analysis and alternative approaches. Natural Areas Journal 27:83-91. 
Morrison, L. W. 2008. The use of control charts to interpret environmental monitoring data. Natural Areas Journal 28:66-73.

Morrison, L. W., and D. E. Bowles. 2006. Recommendations for modifying the sampling protocol for streams in the HTLN prairie parks. Heartland Inventory and Monitoring Network, U.S. National Park Service, Wilson's Creek National Battlefield, Republic, MO.

Moulton, S. R., II, J. L. Carter, S. A. Grotheer, T. F. Cuffney, and T. M. Short. 2000. Methods of analysis by the U.S. Geological Survey National Water Quality Laboratory-processing, taxonomy, and quality control of benthic macroinvertebrate samples. USGS Open-File Report 00-212.

Moulton, S. R. II, J. G. Kennen, R. M. Goldstein, and J. A. Hambrook. 2002. Revised protocols for sampling algal, invertebrate, and fish communities as part of the National WaterQuality Assessment Program. Open-file Report 02-150.

Nakagawa, S., and T. M. Foster. 2004. The case against retrospective power analyses with an introduction to power analysis. Acta Ethologica 7:103-108.

National Park Service (NPS). 2016. Certification guidelines for inventory and monitoring data products. Fort Collins, CO.

Norris, R. H., and A. Georges. 1993. Analysis and interpretation of benthic macroinvertebrate surveys. Pages 234-286 in D. M. Rosenberg and V. H. Resh, editors. Freshwater Biomonitoring and Benthic Macroinvertebrates. Chapman \& Hall, New York, NY.

Olsen, T., B. P. Hayden, A. M. Ellison, G. W. Oehlert, and S. R. Esterby. 1997. Ecological resource monitoring: Change and trend detection workshop report. Bulletin of the Ecological Society of America 78:11-13.

Olson, C. L. 1974. Comparative robustness of six tests in multivariate analysis of variance. Journal of the American Statistical Association 69:894-908.
Parsons M., and R. H. Norris. 1996. The effect of habitat-specific sampling on biological assessment of water quality. Freshwater Biology 36:419-434.

Petersen, J. T. 1997. Annual status report: 1996 stream macroinvertebrate biomonitoring for George Washington Carver National Monument. Prairie Cluster Long-term Ecological Monitoring Program, Program Report 96-001.

Peterson, B. J., J. E. Hobbie, A. E. Hershey, M. A. Lock, T. E. Ford, J. R. Vestal, V. L. Mckinley, M. A. J. Hullar, M. C. Miller, R. M. Ventullo, and G. S. Volk. 1985. Transformation of a tundra river from heterotrophy to autotrophy by addition of phosphorus. Science 229:1383-1386.

Peterson, D. A., and J. R. Zumberge. 2006, Comparison of macroinvertebrate community structure between two riffle-based sampling protocols in Wyoming, Colorado, and Montana, 2000-2001. Scientific Investigations Report 2006-5117. U.S. Geological Survey, Reston, VA.

Peterson, J. T. 1996. Suggested biomonitoring protocol and status of stream quality at six Great Plains national parks. Final Report. Missouri Cooperative Fish and Wildlife Research Unit, University of Missouri, Columbia, MO.

Peterson, J. T., W. M. Rizzo, E. D. Schneider, and G. D. Willson. 1999. Invertebrate biomonitoring protocol for four prairie streams. U.S.

Geological Survey, Northern Prairie Wildlife Research Center, Missouri Field Station, Columbia, MO.

Pettersson, M. 1998. Monitoring a freshwater fish population: Statistical surveillance of biodiversity. Environmetrics 9:139-150.

Peilou, E. C. 1966. The measurement of diversity in different types of biological collections. Journal of Theoretical Biology 13:1-144.

Peitz, D. G., and J. T. Cribbs. 2005a. Bio-monitoring of water quality using aquatic invertebrates and in-stream habitat and riparian condition assessments: status report for Cub Creek, Homestead National Monument of America, Nebraska 1989-2004. U.S. National Park Service, Heartland I\&M Network and Prairie 
Cluster Prototype Monitoring Program, Wilson's Creek National Battlefield, Republic, MO.

Peitz, D. G., and J. T. Cribbs. 2005b. Bio-monitoring of water quality using aquatic invertebrates and in-stream habitat and riparian condition assessment: status report for Pipestone Creek, Pipestone National Monument, Minnesota 1989-2004. U.S. National Park Service, Heartland I\&M Network and Prairie Cluster Prototype Monitoring Program, Wilson's Creek National Battlefield, Republic, MO.

Peitz, D. G., and J. T. Cribbs. 2005c. Bio-monitoring of water quality using aquatic invertebrates and in-stream habitat and riparian condition assessments: status report for Wilson's Creek and Skegg's Branch, Wilson's Creek National Battlefield, Missouri 1988-2004. U.S. National Park Service, Heartland I\&M Network and Prairie Cluster Prototype Monitoring Program, Wilson's Creek National Battlefield, Republic, MO.

Peitz, D. G., and J. T. Cribbs. 2005d. Bio-monitoring of water quality using aquatic invertebrates and in-stream habitat and riparian condition assessments: status report for the Niobrara River, Agate Fossil Beds National Monument, Nebraska 1989-2004 .U.S. National Park Service, Heartland I\&M Network and Prairie Cluster Prototype Monitoring Program, Wilson's Creek National Battlefield, Republic, MO.

Plafkin, J. L., M. T. Barbour, K. D. Porter, S. K. Gross, and R. M. Hughes. 1989. Rapid bioassessment protocols for use in streams and rivers. Benthic macroinvertebrates and fish. EPN44414891001. Office of Water Regulations and Standards, U.S. Environmental Protection Agency, Washington, DC.

Poulton, B. C., T. J. Rasmussen, and C. J. Lee. 2007. Assessment of biological conditions at selected stream sites in Johnson County, Kansas, and Cass County and Jackson counties, Missouri, 2003 and 2004. U.S. Geological Survey Special Investigations Report 2007-5108.
Quinn, J. M., and C. W. Hickey. 1990. Characterization and classification of benthic invertebrate communities in $88 \mathrm{New}$ Zealand rivers in relation to environmental factors. New Zealand Journal of Marine and Freshwater Research 24:387-409.

Rabeni, C. F., R. J. Sarver, N. Wang, G. S. Wallace, M. Weiland, and J. T. Peterson. 1997. Development of regionally based biological criteria for streams of Missouri. A report to the Missouri Department of Natural Resources. Cooperative Fish and Wildlife Research Unit, 112 Stephens Hall, University of Missouri, Columbia, MO.

Rabeni, C. F., N. Wang, and R. J. Sarver. 1999. Evaluating adequacy of the representative stream reach used in invertebrate monitoring programs. North American Benthological Society 18:284-191.

Reice, S. R., and M. Wohlenberg. 1993. Monitoring freshwater benthic macroinvertebrates and benthic processes: measures for assessment of ecosystem health. Pages 287-305 in D. M. Rosenberg and V. H. Resh, editors. Freshwater Biomonitoring and Benthic Macroinvertebrates. Chapman \& Hall, New York, NY.

Resh, V. H., and G. Grodhaus. 1983. Aquatic insects in urban environments. Pages 247-276 in G. Frankie and C. Koehler, editors. Urban Entomology. Praeger Publishers, New York, New York.

Resh, V. H., and J. K. Jackson. 1993. Rapid assessment approaches to biomonitoring using benthic macroinvertebrates. Pages 195-223 in D.M. Rosenberg and V.H. Resh, editors. Freshwater Biomonitoring and Benthic Macroinvertebrates. Chapman \& Hall, NewYork, NY.

Resh, V. H., and E. P. McElray. 1993. Contemporary quantitative approaches to biomonitoring using benthic macroinvertebrates. Pages 159- 194 in D.M. Rosenberg and V.H. Resh, editors. Freshwater Biomonitoring and Benthic Macroinvertebrates. Chapman and Hall, New York, NY. 
Rosenberg, D. M., V. H. Resh, R. S. King. 2008. Use of aquatic insects in biomonitoring. Pages 123-137 in R. W. Merritt, K. W. Cummins, and M. B. Berg, editors, An Introduction to the Aquatic Insects of North America, 4th edition. Kendall Hunt, Dubuque, IA.

Shaver, J. P. 1993. What statistical significance testing is, and what it is not. Journal of Experimental Education 61:293-316.

Steidl, R. J., J. P. Hayes, and E. Schauber. 1997. Statistical power analysis in wildlife research. Journal of Wildlife Research 61:270-279.

Stoehr, A. M. 1999. Are significance thresholds appropriate for the study of animal behaviour? Animal Behaviour 57:F22-F25.

Stone, M. K., and J. B. Wallace. 1998. Long-term recovery of a mountain stream from clear-cut logging: the effects of forest succession on benthic invertebrate community structure. Freshwater Biology 39:151-169.

Taylor, L. R. 1961. Aggregation, variance, and the mean. Nature 189:732-735.

United States Environmental Protection Agency (USEPA). 2004a. Wadeable streams assessment: field operations manual. EPA 841-B-04-004. U.S. Environmental Protection Agency Office of Water, Washington, DC.

United States Environmental Protection Agency (USEPA). 2004b. Wadeable streams assessment: quality assurance project plan. EPA 841-B04005. U.S. Environmental Protection Agency, Office of Water and Office of Environmental Information. Washington, DC.

United States Environmental Protection Agency (USEPA). 2004c. Wadeable streams assessment: site evaluation guidelines, EPA 841-B-04006. U.S. Environmental Protection Agency, Office of Water and Office of Environmental Information. Washington, DC.

United States Environmental Protection Agency (USEPA). 2004d. Wadeable streams assessment: benthic laboratory methods. EPA 841-B-04-007. U.S. Environmental Protection Agency, Office of Water and Office of Environmental Information. Washington, DC.
United States Environmental Protection Agency (USEPA). 2006. Wadeable streams assessment, a collaborative survey of the nation's streams. EPA 841-B-06-002, USEPA, Office of Water, Washington, DC, (www.epa.gov/owow/ streamsurvey).

Usrey, F. D., and J. A. Hinsey. 2006. Characterization of macroinvertebrate community and drift in a tributary of Buffalo National River, National Park Service final report, PMIS No. 82725. Buffalo National River, Harrison, AR.

Utts, J. 1988. Successful replication verses statistical significance. The Journal of Parapsychology 52:305-320.

Wallace, J. B., J. W. Grubaugh, and M. R. Whiles. 1996. Biotic indices and stream ecosystem processes: results from an experimental study. Ecological Applications 61:140-151.

Wentworth, C. K. 1922. A scale of grade and class terms for clastic sediments. Journal of Geology 30:377-392.

Wilton, T. 2004. Biological assessment of Iowa's wadeable streams. Project Report. Iowa Department of Natural Resources, Des Moines, Iowa.

Winner, R. W., M. W. Boessel, and M. P. Farrell. 1980. Insect community structure as an index of heavy-metal pollution in lotic ecosystems. Canadian Journal of Fisheries and Aquatic Science 37:647-655.

Yoccoz, N. G. 1991. Use, overuse, and misuse of significance tests in evolutionary biology and ecology. Bulletin of the Ecological Society of America 72:106-111.

Yoder, C. O., and E. T. Rankin. 1995. Biological criteria program development and implementation in Ohio. Pages 109-144 in W. S. Davies and T. P. Simon, editors. Biological Assessment and Criteria. Lewis Publishers, Boca Raton, FL. 


\section{Appendix A. Maps of Stream Locations}

Maps A-1 through A-9 show the lower sampling reach boundaries of stream locations in network parks.

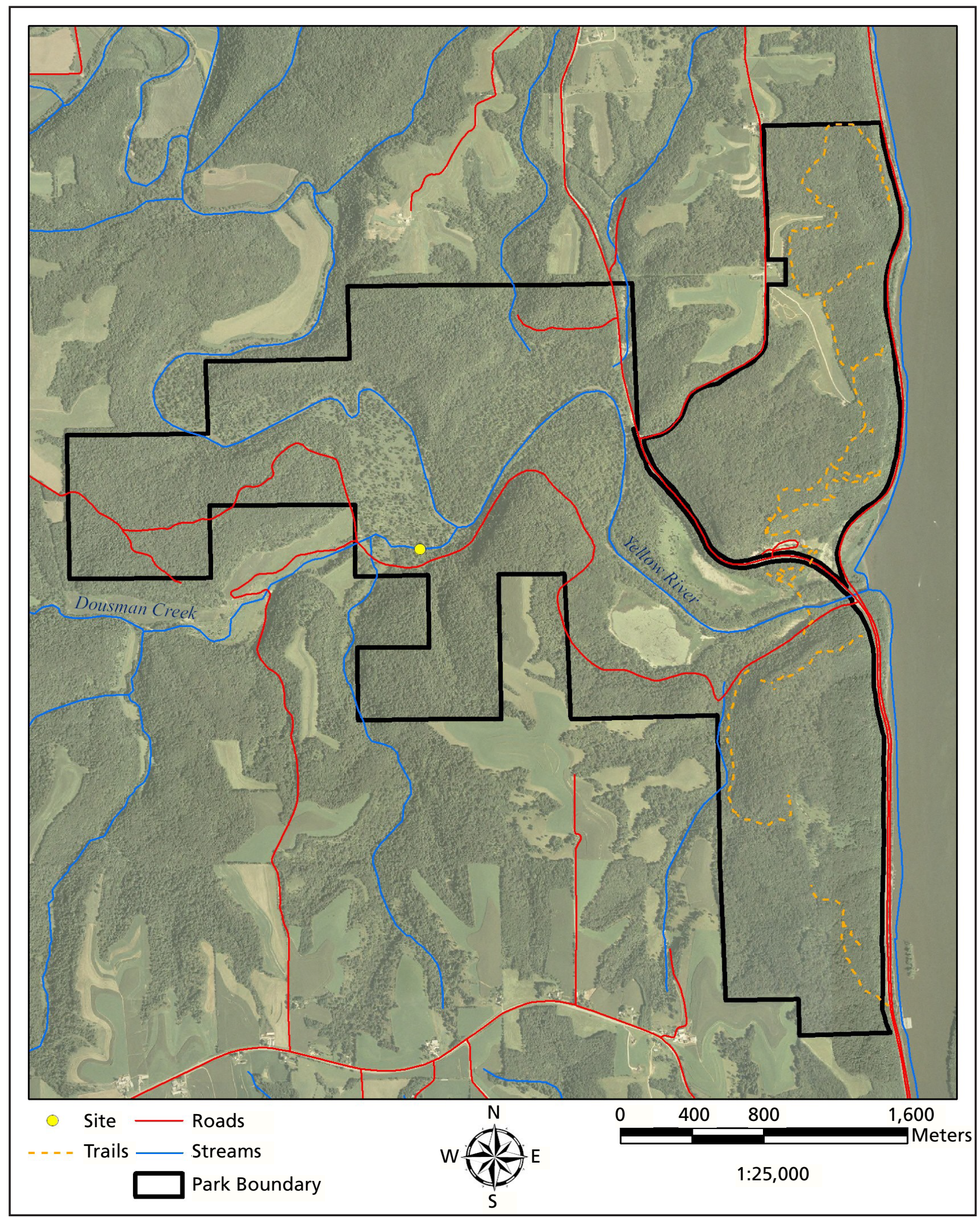

Map A-1. Map showing the approximate lower sampling reach location for Dousman Creek, EFMO. 


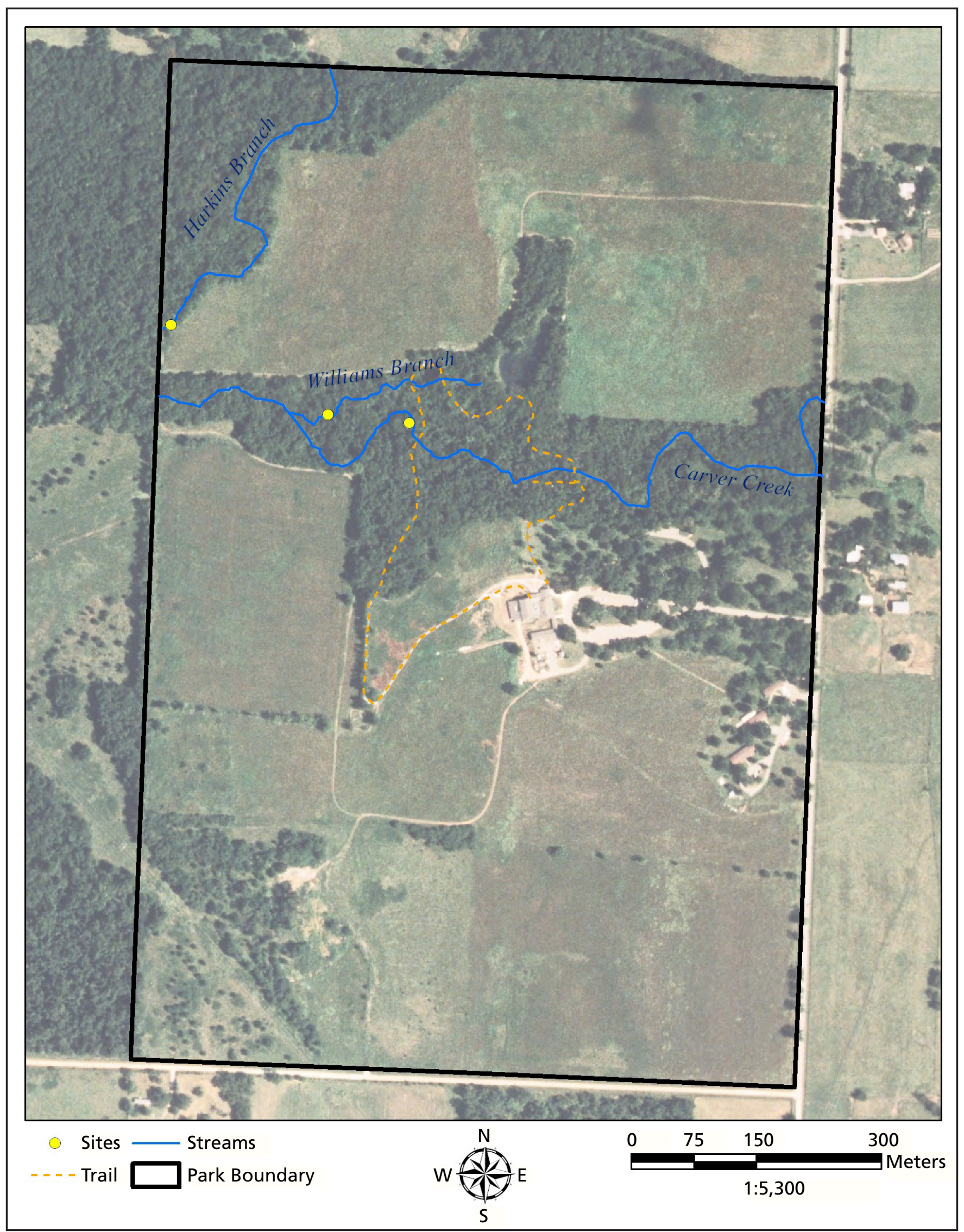

Map A-2. Map showing the approximate lower sampling reach locations for Carver Creek, Williams Branch and Harkins Branch, GWCA. 


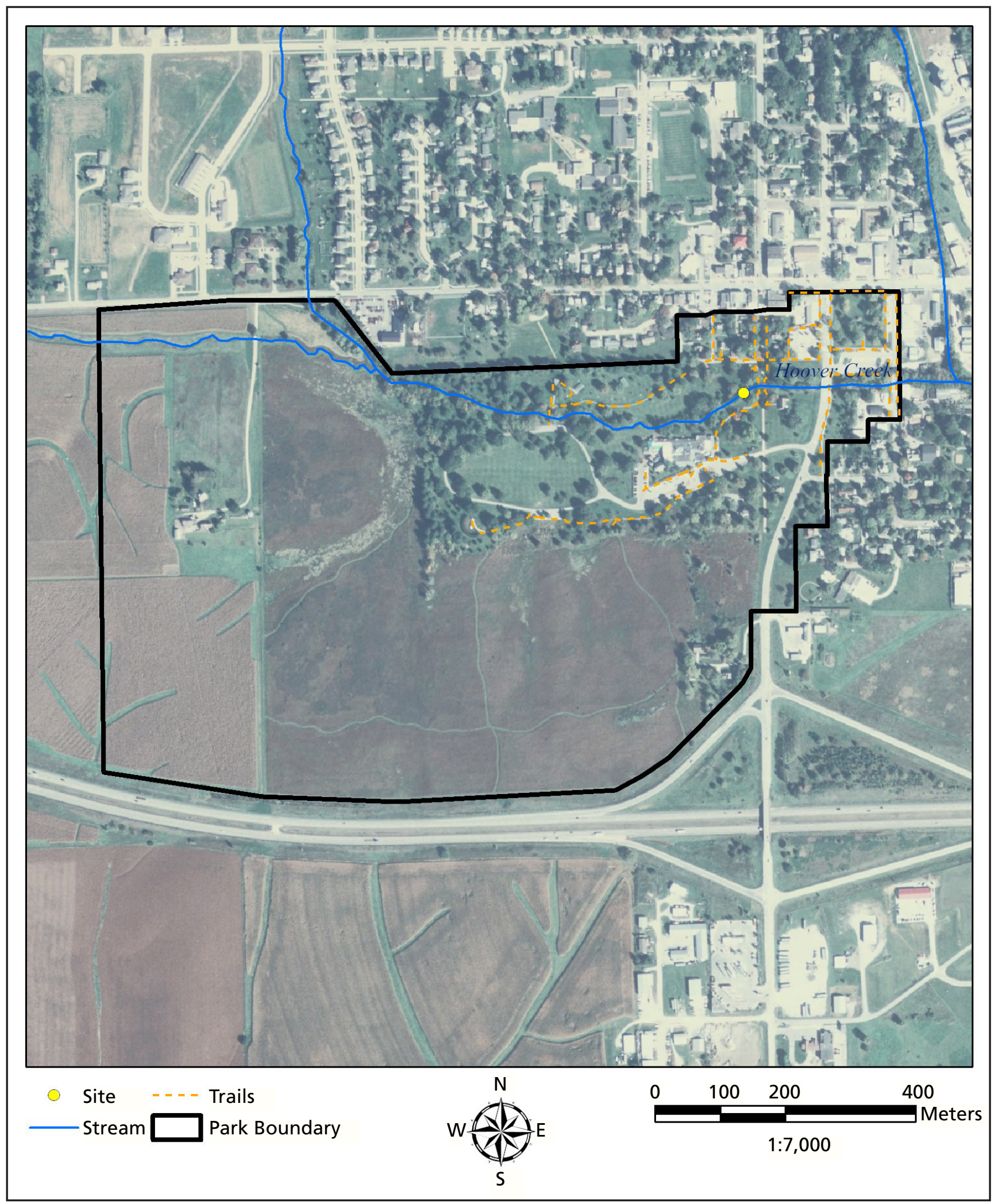

Map A-3. Map showing the approximate lower sampling reach location for Hoover Creek, HEHO. 


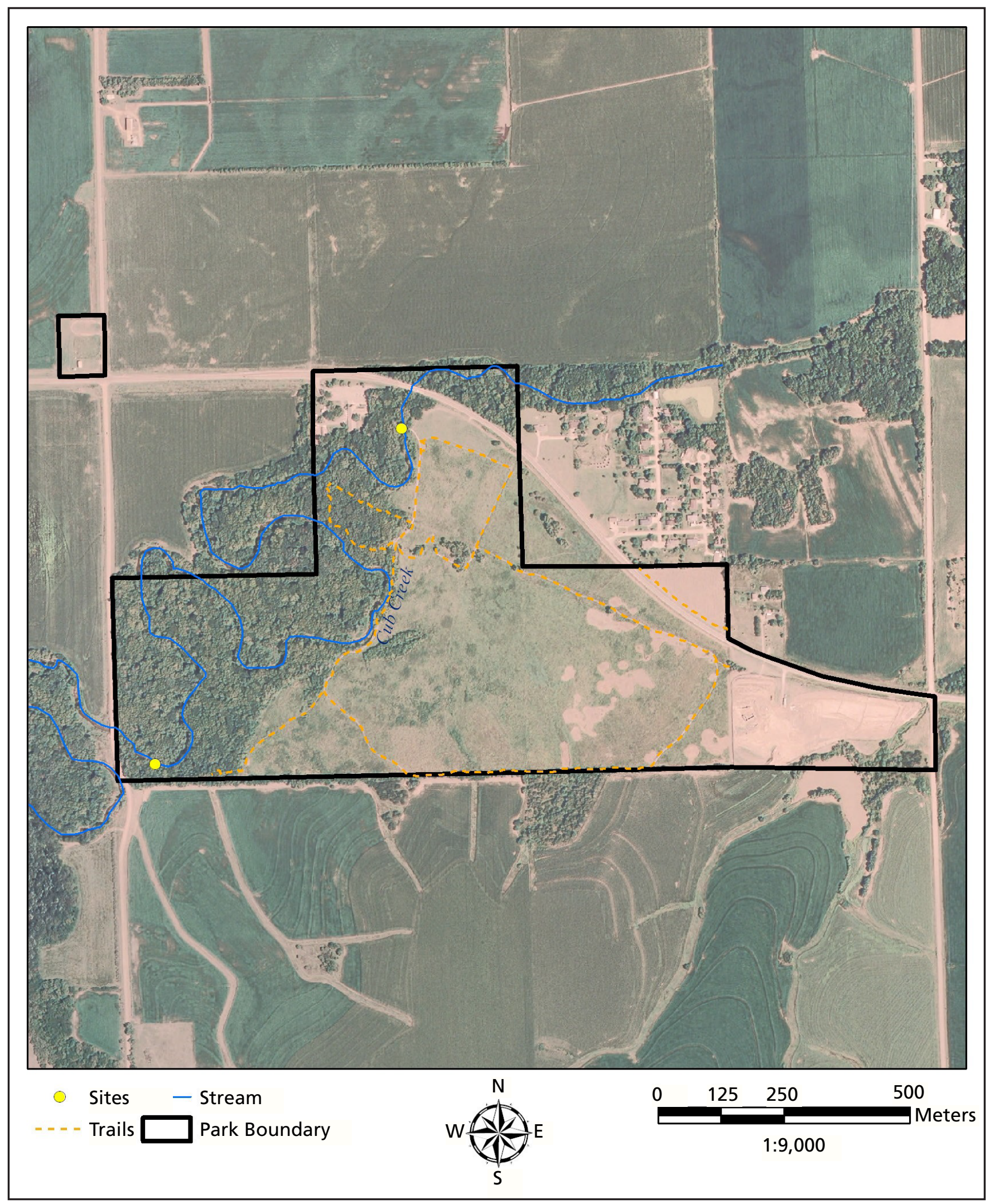

Map A-4. Map showing the approximate upper and lower sampling locations for Cub Creek, HOME. 


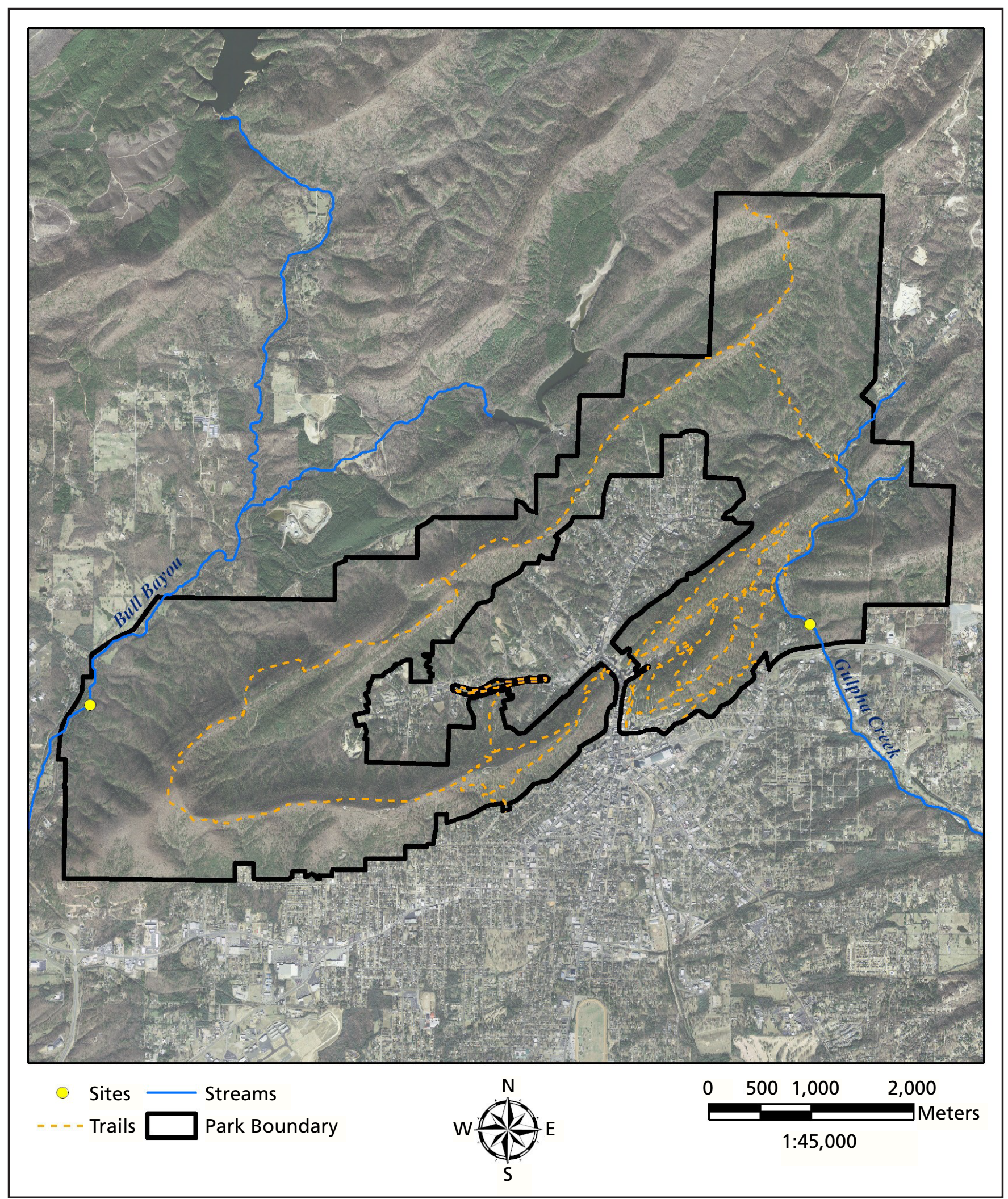

Map A-5. Map showing the approximate lower sampling reach locations for Bull Bayou and Gulpha Creek, HOSP. 


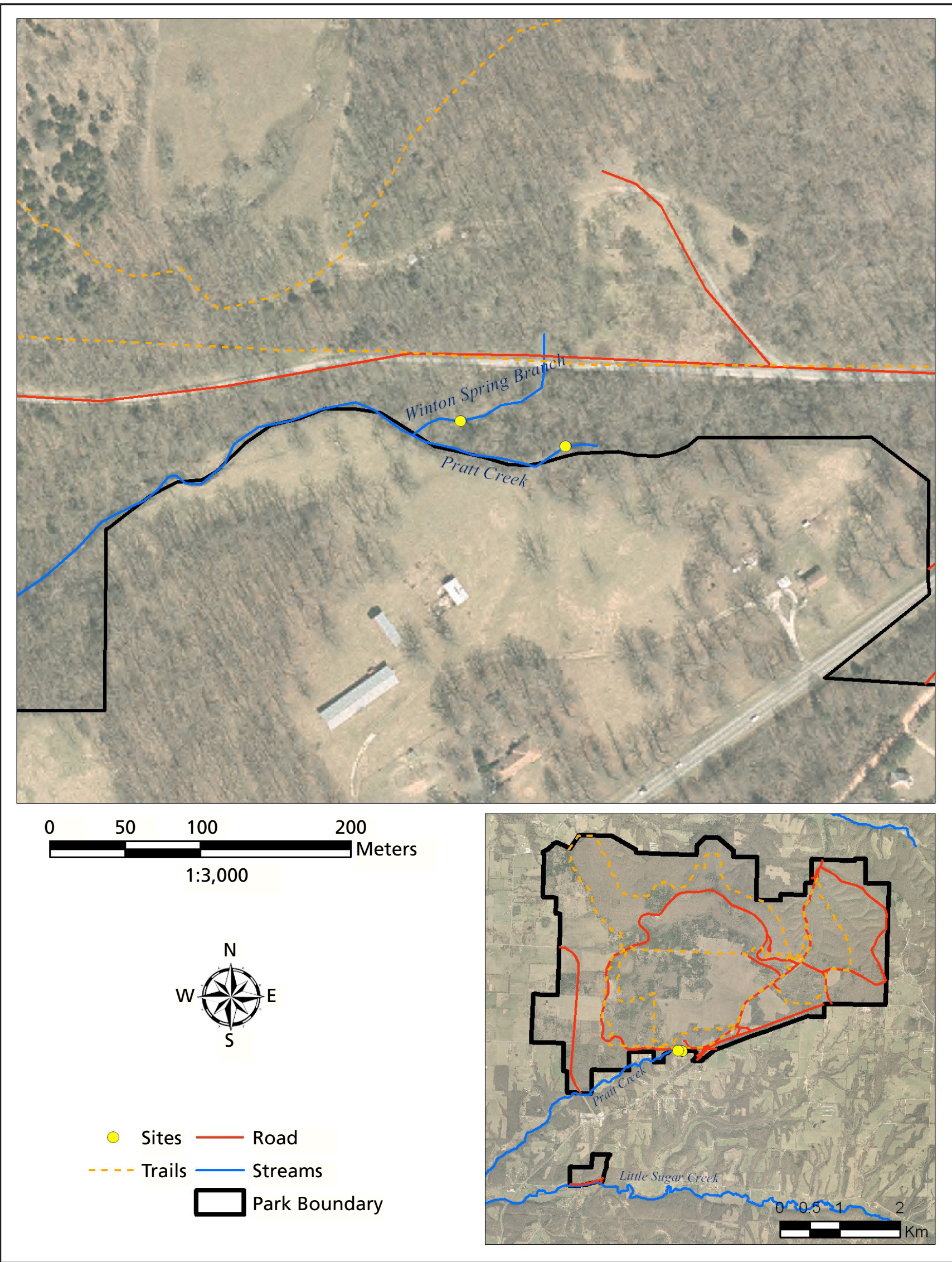

Map A-6. Map showing the approximate lower sampling reach locations for Pratt Creek and Winton Spring Branch, PERI. 


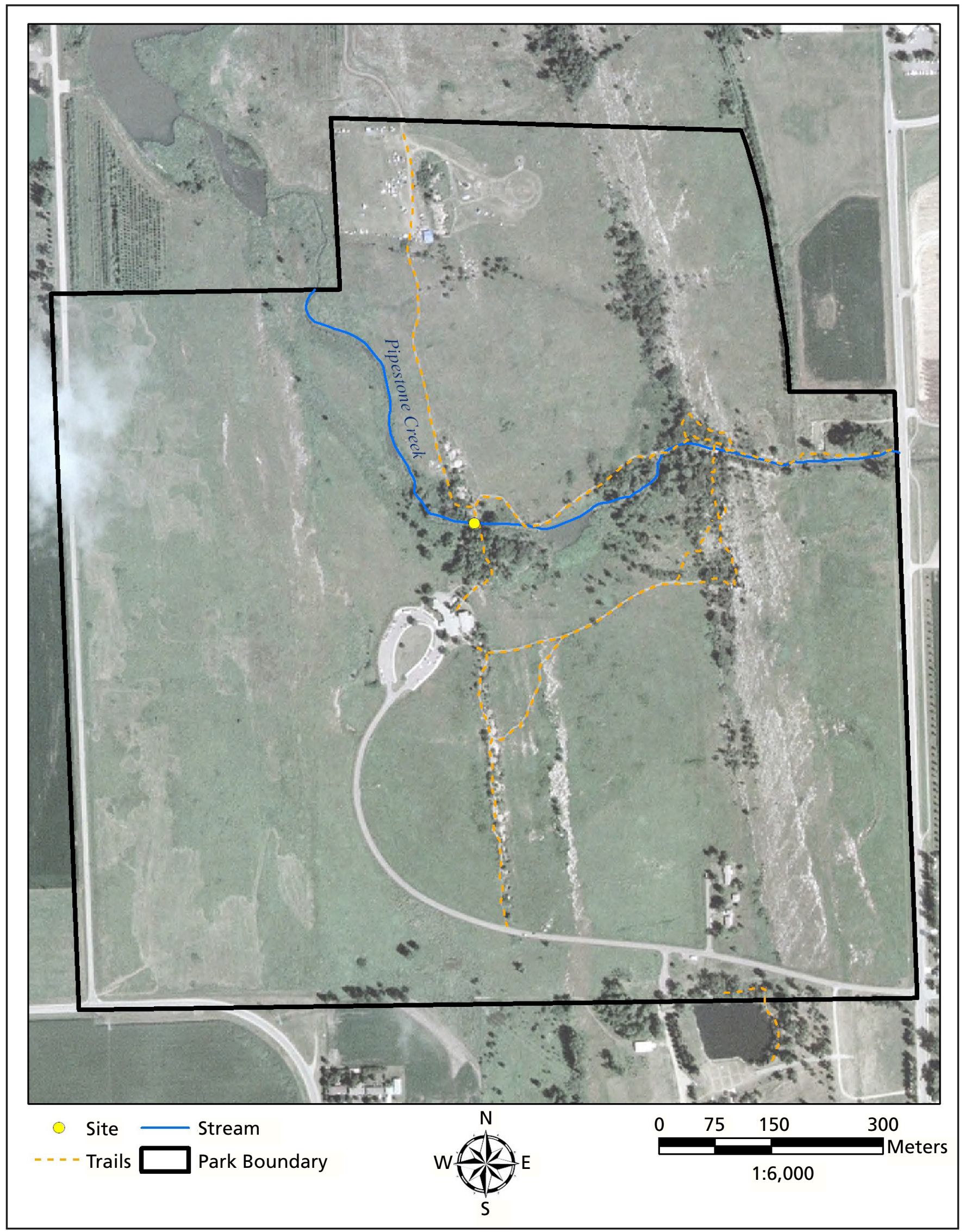

Map A-7. Map showing the approximate lower sampling reach location for Pipestone Creek, PIPE. 


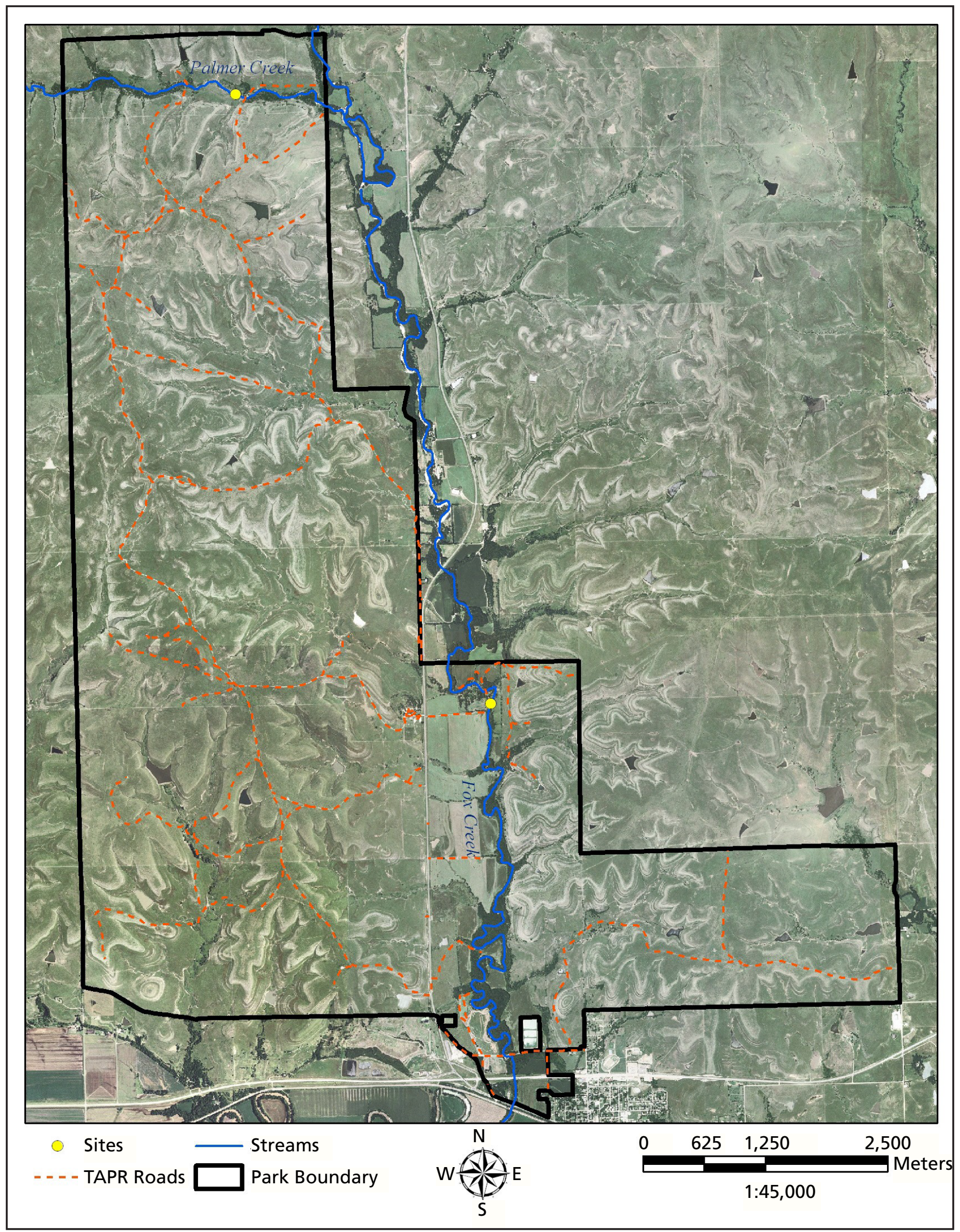

Map A-8. Map showing the approximate lower sampling reach locations for Fox Creek and Palmer Creek, TAPR. 


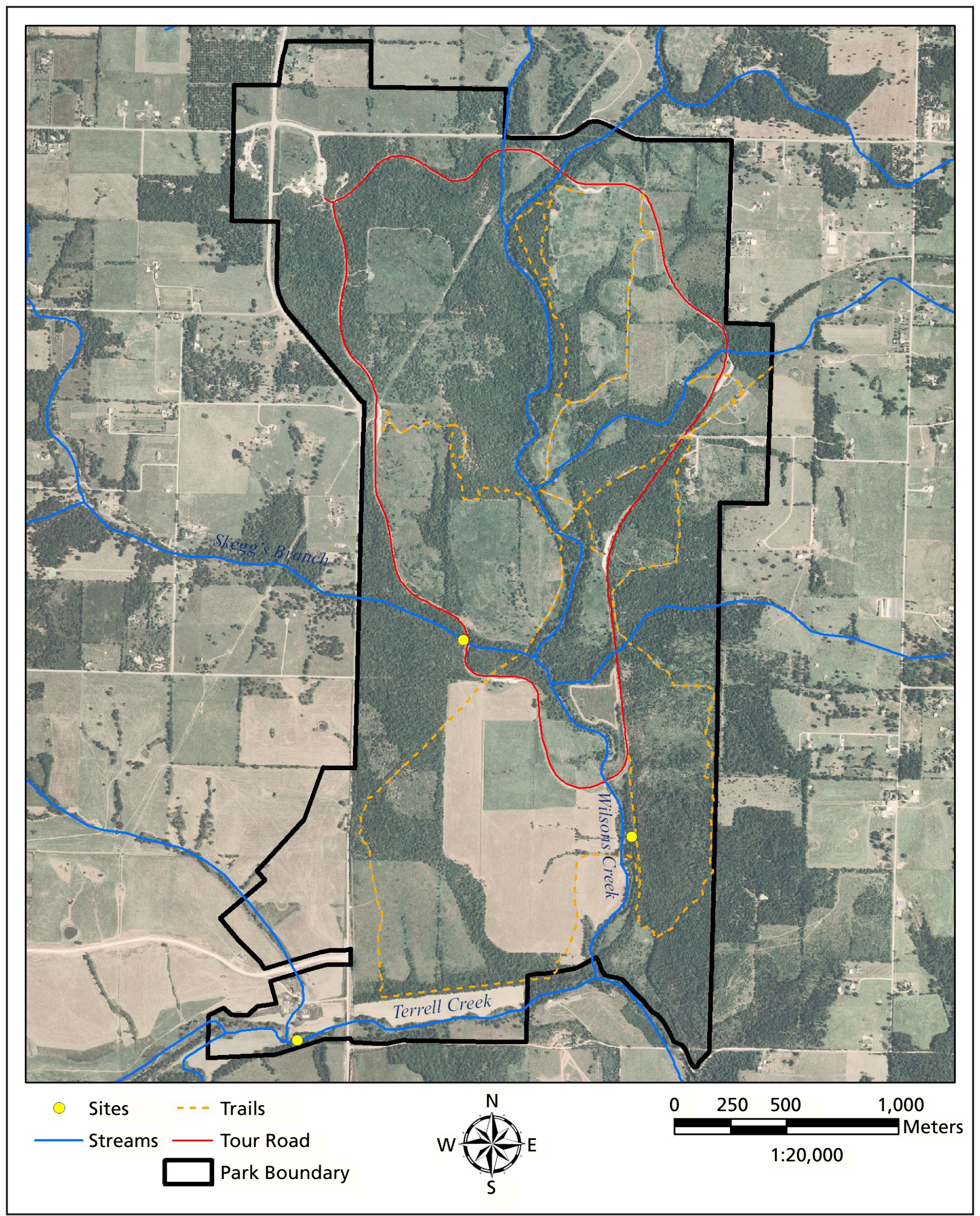

Map A-9. Map showing the approximate lower sampling reach locations for Wilson's Creek, Skegg's Branch, and Terrell Creek, WICR. 

The Department of the Interior protects and manages the nation's natural resources and cultural heritage; provides scientific and other information about those resources; and honors its special responsibilities to American Indians, Alaska Natives, and affiliated Island Communities.

NPS 920/175078, February 2021 
National Park Service

U.S. Department of the Interior

Natural Resource Stewardship and Science

1201 Oak Ridge Drive, Suite 150

Fort Collins, Colorado 80525 